\title{
(Des)construindo relações entre agentividade, causa e morfologia em verbos de mudança de estado do português brasileiro*
}

(De)constructing relations among agentivity, cause and morphology in change of state verbs in brazilian portuguese

Indaiá de Santana Bassani (Universidade Federal de São Paulo, Guarulhos, São Paulo, Brasil)

\section{RESUMO:}

Este artigo propõe a classificação empírica e análise de 136 verbos de mudança de estado em seis tipos de eventos (Incoativo, Causativo, Causativo subespecificado para [ag], Totalmente subespecificado, Causativo agentivo estrito e Causativo estrito com voice) com base em seus comportamentos frente a testes de formação de sentença transitiva com agente, transitiva com causa, intransitiva e passiva. A partir dessa classificação, propomos uma análise de decomposição sintática do evento que atenta, ao mesmo tempo, para a tipologia semântica da raiz e para a morfologia verbal e suas possíveis relações com o argumento externo. Para tal, utilizamos como base teórica o modelo da Morfologia Distribuida.

Palavras-chave: Verbos de mudança de estado. Causa. Agentividade. Morfologia Distribuída.

\footnotetext{
* Programa de Pós-graduação em Letras da UNIFESP; Grupo de pesquisa INFOLINC - Investigações (in)formais em lingua(gem) e cognição da UNIFESP; Grupo de Estudos em Morfologia Distribuída da Universidade de São Paulo (GREMD-USP). Agradeço aos pareceristas anônimos pelas valiosas sugestões que levaram ao aprimoramento do manuscrito. 


\begin{abstract}
This paper proposes an empirical classification and analysis of 136 change of state verbs into six event types (Incoative, Causative, Causative underspecified for [ag], Totally underspecified, Strictilly Agentive Causative, and Strictilly Causative with voice) based on their behavior in face of the following tests: formation of transitive sentences with agents as external arguments, transitives with cause as external arguments, intransitives and passives. Departing from this classification, we propose a syntatic decomposition analysis of the event which regards at the same time the roots semantics typology, the verbal morphology and its possible relations to the external argument. In order to achieve that, a Distributed Morphology approach is assumed.
\end{abstract}

Key-words: Change of state verbs. Cause. Agentivity. Distributed Morphology.

\title{
1. Introdução
}

Verbos de mudança de estado (doravante VME) denotam um evento em que há mudança de estado sofrida pelo argumento interno. Essa mudança pode ser física (ex. endurecer o chocolate) ou psicológica (ex. acalmar a criança). Esses verbos podem ser morfologicamente complexos, com a presença de prefixos e, em menor grau, de sufixos. Alguns exemplos dessas possibilidades a seguir, em que se notam os prefixos $a-, e N$ - e $e S$ - e os sufixos $-e c-$ e $-i z-{ }^{1}$ :
(1) $\quad \mathrm{a}-\ldots-\varnothing-(\mathrm{a})$
(amaciar)
(2) $\mathrm{eN}-\ldots-\varnothing-(\mathrm{a})$
(engordar)
(3) eS-...-Ø-(a)
(esvaziar)
(4) $\mathrm{eN}-\ldots$-ec(e)
(empobrecer)
(5) $\quad$ eS-...-ec(e)
(esclarecer)
(6) $\quad \mathrm{a}-\ldots-\mathrm{iz}(\mathrm{a})$
(aterrorizar)

O objetivo do presente trabalho é propor uma classificação empírica de 136 VMEs morfologicamente complexos em seis subtipos (Incoativo, Causativo, Causativo subespecificado para [ag], Totalmente subespecificado, Causativo agentivo estrito e Causativo estrito com Voice) com base em seu comportamento frente a testes de formação de sentença transitiva com agente, transitiva com causa, intransitiva e passiva. Como tais verbos contém prefixos em sua totalidade e sufixos, em menor grau, a partir desta classificação,

1. A forma $a$ - representa as realizações $a$ - e $a d-, e N$ - representa os alomorfes en-, em-, e- e in-, e $e S-$ representa as possibilidades gráficas es- e ex-. 
propomos uma decomposição sintática do evento que atente, ao mesmo tempo, para a tipologia da raiz, para a morfologia do verbo e para as relações com o Argumento Externo (doravante AE). Para isso, utlizamos como arcabouço teórico o modelo da Morfologia Distribuída (doravante MD) (Halle; Marantz 1993). O corpus de análise é proveniente de Bassani (2013), onde podem ser encontradas a metodologia de seleção e a classificação ampla dos dados.

$\mathrm{O}$ artigo se organiza da seguinte forma: na seção 2 , há refinamentos descritivos relativos às propostas anteriores e uma descrição morfológica dos dados e; na seção 3, os pressupostos teóricos, a classificação em tipos de eventos e a proposta de análise estrutural são apresentados; a seção 4 apresenta as considerações finais.

\section{Verbos de Mudança de Estado}

Na literatura, os VMEs são frequentemente classificados como deadjetivais. Entretanto, o tipo categorial da base não é determinante para a formação desse tipo de verbo: tanto substantivos quanto adjetivos formam verbos dessa classe e podem denotar propriedades/características adquiridas pelo argumento interno no evento. Assim, a divisão em verbos deadjetivais e denominais é desnecessária. Isto se assumirmos que são verbos derivados de palavras. Diferentemente, assumimos que nos dois casos se trata da interpretação adquirida a partir de propriedades da raiz, que pode também formar substantivos e adjetivos. Algumas propriedades denotadas pelas raízes que geralmente formam adjetivos podem ser graduais e são, portanto, predicados escalares. Por exemplo, endurecer não significa, necessariamente 'tornar duro' (como se existissem somente dois estados: 'duro X não duro'), mas frequentemente significa 'tornar (mais) duro'. As raízes que formam nomes não apresentam essa especificidade. Pereira (2007) apresenta a seguinte Estrutura Lexical-Conceitual para o verbo endurecer:

\section{(7) [[x AGIR] CAUSAR [y IR PARA DURO]]}

Cançado e Godoy (2012) (doravante CG) descrevem três subtipos de VMEs: incoativos, causativos/agentivos e estritamente causativos. As autoras apresentam como principais propriedades gerais dessa macroclasse o fato de acarretarem uma mudança de estado que é denotada pela raiz (8) e de participarem de alternância causativo-incoativa, como em (9). O acarretamento é usado para revelar o resultado.

(8) a. O calor amadureceu a banana.

b. A banana ficou madura.

(9) a. O calor amadureceu a banana.

b. A banana amadureceu. 
Tais testes permitem a diferenciação de tipos de VMEs. No entanto, a explicação sobre a projeção de tais verbos na estrutura argumental é demasiadamente simplificada. As autoras sugerem que os três tipos de verbos projetarão do mesmo modo os seus argumentos internos em uma estrutura baseada na diádica composta de Hale e Keyser (2002), vejamos (10):

(10)

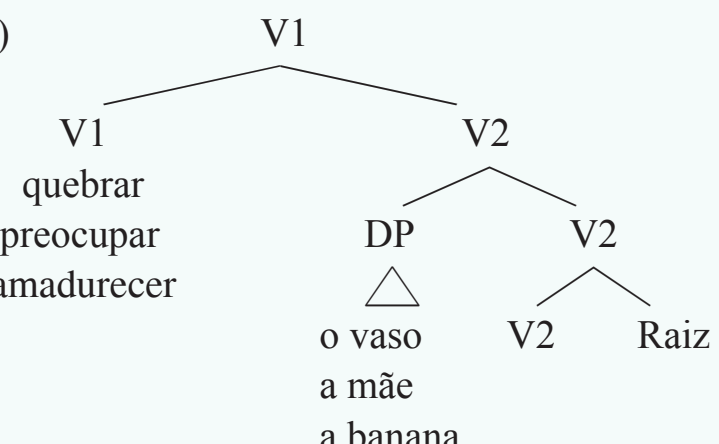

Primeiramente, as autoras afirmam que o fato de os três verbos se relacionarem de modo diferente com seus Argumentos Externos (AEs) é irrelevante para a projeção dos mesmos na estrutura sintático-lexical, apesar de mostrarem propriedades morfossintáticas sensíveis a essa diferença: a passivização, a indeterminação do sujeito e a presença do clítico se, como veremos detalhadamente. Assumir que os três tipos de verbos são projetados em uma estrutura argumental idêntica, como na representação acima, é assumir que os AEs serão sempre projetados por um mesmo tipo de V1, o que simplifica e neutraliza as suas particularidades. É fato que cada tipo de raiz e verbalizador apresentam propriedades diferentes na sua relação com a agentividade, mas essa estrutura não consegue representar causa e agentividade por núcleos distintos, como propõem Alexiadou, Anagnostopoulou e Schäfer (2006) e, também, CG em suas representações semânticas. As noções de causa e agentividade estão amalgamadas na representação do núcleo V1. Por isso, é necessário postular um nível semântico pré-sintático que abarca essas noções neste tipo de sintaxe lexical. Além disso, a estrutura não atenta para a complexidade morfológica de um verbo derivado, como amadurecer por exemplo, em que a presença de afixos é ignorada: esse verbo claramente complexo é inserido como um bloco no núcleo V2. Essa crítica pode ser estendida à representação de Pereira em (7).

Com relação à base de formação dos verbos em estudo, em primeiro lugar, nossos dados revelam que o estado nem sempre é denotado somente pela raiz. Assim, o primeiro fator importante é que a raiz não precisa denotar ela mesma um estado para que se derive um VME do argumento interno. A base pode conter por si só uma estrutura complexa. Identificamos as seguintes formas de denotar um estado:

a) Raiz de estado acategorial: a raiz morfologicamente simples denota a propriedade que será adquirida pelo argumento interno. Trata-se 
de um predicado. Um exemplo prototípico está no verbo encher: a raiz che(i)-, que é a mesma que forma o adjetivo cheio(a), denota sozinha um estado e não há necessidade de postular formação de verbo deadjetival, que deveria ser *encheiar. A maior parte dos VMEs do corpus é derivada a partir dessas raízes. Outros exemplos são: alargar, alongar, amansar, apodrecer, amadurecer, emagrecer, empobrecer, encurtar, engordar, esfriar, esvaziar.

b) Por um estado derivado: a raiz não denota prototipicamente um estado, ou seja, não há um predicado a ser saturado. A característica de estado pode ser extraída de alguma propriedade da entidade prototipicamente denotada pela raiz (como em empedrar, em que a propriedade relevante é "sólido"), ou um adjetivo pode ser derivado a partir da raiz que denota tipicamente uma entidade, como em abrasileirar (cuja raiz é a que deriva o nome Brasil) ou a partir de raízes que denotam eventos embebedar (cuja raiz é a mesma que forma o verbo beber) criando-se um predicado por meio de um núcleo adjetival que é realizado pelos sufixos -eiro e -ado, respectivamente. Outros exemplos são: envergonhar, aterrorizar, atormentar, alagar, embebedar, abrasileirar.

Uma evidência para a divisão nesses dois subgrupos é o fato de que a paráfrase de acarretamento/resultado formada para os verbos de raízes estativas é normalmente feita com o adjetivo atributivo simples ao passo que os verbos formados a partir de bases de estados derivados somente apresentam acarretamento com o particípio, ou com algum tipo de locução adjetival (um PP que introduz a raiz, em geral, formadora de substantivos) que pode apresentar uma comparação quando a propriedade relevante é extraída da raiz (ficou como pedra/lago) ou pode ser nucleado por com, especialmente nos VMEs psicológico (ficou com vergonha).

(3) Acarretamentos com raízes que prototipicamente denotam estados:
a. Enfraquecer $=$ ficar $(+)$ fraco
b. Esclarecer $=$ ficou $(+)$ claro
c. Adoçar $=$ ficou $(+)$ doce

(4) Acarretamentoscom raízes quenãodenotam estados prototipicamente:

a. Atormentar $=$ ficou atormentado $/$ \#tormento

b. Empedrar $=$ ficou empedrado/ como pedra $/$ \#pedra

c. Envergonhar $=$ ficou envergonhado $/$ com vergonha $/$ \#vergonha

Os particípios podem também ser usados como acarretamentos nos VMEs com raízes estativas: ficou envelhecido/ enfraquecido, mas, nesse caso, revelam o estado resultante como um todo e não o resultado da mudança veiculado pela camada mais interna do subevento incoativo. 
Os dados acima nos levam a assumir com a teoria da MD a noção de compatibilidade ou licenciamento estrutural, definida a seguir: a estrutura não é projetada dos itens lexicais - os itens lexicais (raízes acategoriais) é que são licenciados em determinadas estruturas de eventos e negociam seu significado com elas (Scher; Medeiros; Minussi 2011:185-6). Assim, o achado com relação ao tipo de raiz que compõe os VMEs é uma contribuição: não são as raízes de estado que projetam um VME (ou adjetivos, como em muitas propostas lexicalistas), mas esse tipo de raiz é licenciado na estrutura de evento compatível. Prova disso é que mesmo uma raiz sem nenhuma possibilidade de projeção lexical, ou de atribuição de papeis temáticos/semânticos, (como as que formam lago, pedra, tormento) pode ser manipulada a fim de obter a propriedade necessária para seu correto licenciamento.

Nos dados, os sufixos estão distribuídos do seguinte modo (observe tabela abaixo): de 136 verbos, 39 realizam-se com o sufixo -ec-, dois com -iz-, e dois com - $e$ - e a maioria dos verbos não apresenta sufixos fonologicamente realizados ( 93 verbos). Por serem dados escassos, não faremos considerações sobre - $e$ - neste artigo. Faremos uma breve reflexão sobre -iz- a partir da adição de dados somente sufixados adiante.

Tabela 1 - Sufixos e VMEs

\begin{tabular}{ccl}
\hline Sufixo & Total & \multicolumn{1}{c}{$\begin{array}{c}\text { Mudança de Estado } \\
\text { Exemplos }\end{array}$} \\
\hline -e- & 2 & esverdear, assenhorear \\
-ec- & 39 & amanhecer, empobrecer, esclarecer \\
-iz- & 2 & atemorizar, encolerizar \\
$\varnothing$ & 93 & adoçar, engrossar, esvaziar \\
\hline Total & $\mathbf{1 3 6}$ & \\
\hline
\end{tabular}

Se considerarmos outros tipos semânticos, não enfocados neste artigo², observamos que o sufixo -ec-ocorre exclusivamente em VMEs. O sufixo -iz-é quase exclusivo: das únicas três realizações do corpus, duas estão nessa classe. No entanto, o sufixo -iz- ocorre em número muito reduzido em concomitância com a presença de prefixos. Assim, o que podemos afirmar é que a presença do sufixo -ec- está correlacionada com a classe de VMEs. Em Bassani (2011), sugerimos que o sufixo -ec- poderia ser a realização morfológica do operador BECOME de Parsons (1990). Porém, duas observações devem ser feitas. Primeiro, tal correlação não é biunívoca: não é verdade que, para que se derive um VME, há de se compor morfologicamente esse verbo com o sufixo -ec-

2. Bassani (2013) propõe quatro classes de verbos de mudança do argumento interno: de estado, de lugar, de posse e de configuração. 
(i.e. secar, molhar, amaciar). Assim, devemos afirmar que -ec- poderia ser uma das realizações fonológicas de BECOME. Segundo, tendo assumido uma teoria como a MD, temos que -ec- deve ser a realização fonológica de um categorizador verbal, dado que se encontra em distribuição complementar com outros sufixos verbais. Um dos objetivos deste trabalho é verificar se existe alguma correlação entre a presença de -ec-e subtipos de VMEs.

Em seguida, a pergunta natural que se coloca, e a hipótese a ser testada, é se há alguma correlação entre o tipo de prefixo e essa classe. Acedo-Matellán (c.p.) aponta que, em catalão, o prefixo en/-em- veicula mudança de lugar ao passo que o prefixo $a$ - veicula mudança de estado. Não concordamos com a afirmação do autor, pois tal divisão não se observa empiricamente para o catalão ${ }^{3}$, e afirmamos com certeza para o português que tal divisão de tarefas entre $a$ - e $e N$ - não se concretiza. No português, o prefixo $e N$ - tem ampla realização dentro da classe de VMEs: 53 de 136, co-ocorrendo ou não com sufixos. O prefixo $a$ - é ainda o mais numeroso, com 75 ocorrências. O prefixo $e S$ - tem pouca representatividade, totalizando apenas 8 verbos.

Tabela 2 - Prefixos e VMEs

\begin{tabular}{|c|c|c|}
\hline \multicolumn{3}{|r|}{ Mudança de Estado } \\
\hline Prefixo & & Exemplos \\
\hline a & 75 & agravar, apodrecer, atemorizar, amadurecer \\
\hline $\mathrm{eN}$ & 53 & encurtar, enfraquecer, empobrecer, engordar \\
\hline eS & 8 & esvaziar, esclarecer, esquentar \\
\hline Total & 136 & \\
\hline
\end{tabular}

A próxima pergunta é se existe, como afirmam Rio-Torto (2004) e Pereira (2007), uma correlação tão forte entre sufixos e prefixos nos verbos parassintéticos que leva esses autores a considerá-los como verbos circunfixados. Nesse sentido, como muitos trabalhos sugerem, a realização do prefixo $\mathrm{eN}$ em VMEs seria fruto de uma dependência desse prefixo com o sufixo -ec-. Novamente, nossos dados mostram que esse não é o caso: o sufixo -ec- realizase com as três formas prefixais, como vemos na tabela abaixo. Ainda que haja co-ocorrência numericamente maior com $e N$-, devemos tratar tal fato em forma de tendência e não como evidência empírica para a postulação de um circunfixo. Verificaremos, então, se é possível estabelecer relação entre a forma prefixal e o subtipo de evento internamente a essa classe. 
Tabela 3 - Prefixos vs. sufixos e VMEs.

\begin{tabular}{cllccc}
\hline $\begin{array}{c}\text { Mudança de estado } \\
\text { Prefixo }\end{array}$ & Sufixo & & & & \\
a & 1 & 10 & 1 & 63 & 75 \\
eN & 0 & 27 & 1 & 25 & 53 \\
eS & 1 & 2 & 0 & 5 & 8 \\
\hline Total & $\mathbf{2}$ & $\mathbf{3 9}$ & $\mathbf{2}$ & $\mathbf{9 3}$ & 136 \\
\hline
\end{tabular}

Após apresentar esses resultados, exploraremos inicialmente a hipótese da literatura de que o sufixo -ec- está somente atrelado a mudanças de estado internamente causadas e de que -iz- está associado às externamente causadas (Oliveira 2009).

No que se segue, utilizaremos a seguinte estratégia: primeiramente, descreveremos as propriedades e os tipos de VMEs, nos pautando, sobretudo, nos trabalhos de CG, Alexiadou, Anagnostopoulou e Schäfer (2006) e Alexiadou (2014) e mostraremos como (e se) nossos dados se encaixam nessas classificações. A escolha por uma decomposição sintática se justifica, principalmente, pela possibilidade que essa teoria nos dá de abrigar os morfemas em núcleos funcionais. Para fins de clareza de exposição, antes dos detalhamentos e motivações para a análise, resumimos os seus principais elementos.

\section{Proposta de análise dos dados}

Nesta seção, apresentamos uma análise para o licenciamento das raízes em determinadas estruturas baseada nos seguintes pressupostos:

a) As raízes (representadas por $\sqrt{ }$ ) pertencem a um determinado tipo semântico, inicialmente especificado no inventário de raízes da língua que, no que nos importa aqui, podem ser de tipo Estado e Entidade. No entanto, essa especificação pode sofrer coerção estrutural decorrente da combinação da raiz com outros elementos;

b) As raízes de tipo Estado podem ser subclassificadas em dois tipos: as que denotam estados conceitualizados como internos/inerentes ou estados não internos/inerentes. Como tais propriedades são relevantes para o licenciamento estrutural, as representamos por meio do traço [ \pm int]:

Traço semântico [int]: traço que especifica se uma raiz que denota um estado é prototipicamente interpretada como fruto de uma mudança interna e espontânea, conhecida como internamente causada [+int], ou se é interpretada como fruto de uma mudança causada por força 
externa [-int]. Se a raiz for especificada como [-int], uma projeção VoiceP será necessária;

c) $\mathrm{O}$ argumento interno é introduzido na estrutura pelo núcleo $\mathrm{R}$ (Relacionador, cf.: (13)) e não diretamente pela raiz. Em alguns verbos, esse núcleo é fonologicamente realizado por um prefixo (para argumentação sobre tal escolha, cf.: Bassani; Minussi 2015);

d) $\mathrm{O}$ traço [int] tem especificação inicial na raiz, mas sua especificação final será dada em RP (de Frase Relacional), conjuntamente com o argumento interno;

e) Todas as raízes/RPs são licenciadas como complementos de $v$;

f) Causa não é um traço, mas o resultado de uma relação estrutural;

g) Os verbalizadores podem ser de dois tipos: os que podem se combinar a uma projeção de Voice $\left(v_{[+ \text {voice }}\right)$ e os que nunca se combinam a uma projeção de Voice $\left(v_{\text {[-voice] }}\right)$;

h) A projeção Voice pode ser especificada como [ \pm ag]. A especificação do traço $[\mathrm{ag}]$ de Voice define como o elemento em sua posição de especificador será interpretado (agente vs. não agente) e depende dos traços de $\nu \mathrm{P}$ (que inclui $\mathrm{RP}$ e, consequentemente, o argumento interno e a raiz);

i) As raízes/RPs [-int] são prototipicamente licenciadas em estruturas $\operatorname{com} v_{[+ \text {voice }]}$;

j) As raízes/RPs [+int] nunca são licenciadas em uma estrutura com Voice. Contudo, são licenciadas pelo núcleo $v_{\text {[-voice] }}$, que pode licenciar opcionalmente uma posição direta de especificador, que nunca é interpretada como [+ag] (seguindo Alexiadou (2014)).

Em suma, os traços de raiz/RP (de estado) são [ \pm int]; os verbalizadores são $v_{\text {[ }} \pm_{\text {voice] }}$ e a projeção de Voice pode ser especificada como $[ \pm \mathrm{ag}]$. RPs que contêm raízes que denotam entidades (e que não sofreram coerção) não contêm o traço [int], mas se comportam estruturalmente como raízes/RPs especificadas com o traço [-int] porque a mudança de estado não pode ser interpretada como internamente causada, ou seja, fazem parte de eventos externamente causados. Assumimos que as relações de Causa e Become são estruturais de $v$ com RP e de $\mathrm{R} \operatorname{com} \sqrt{ }$, respectivamente: 
(13)

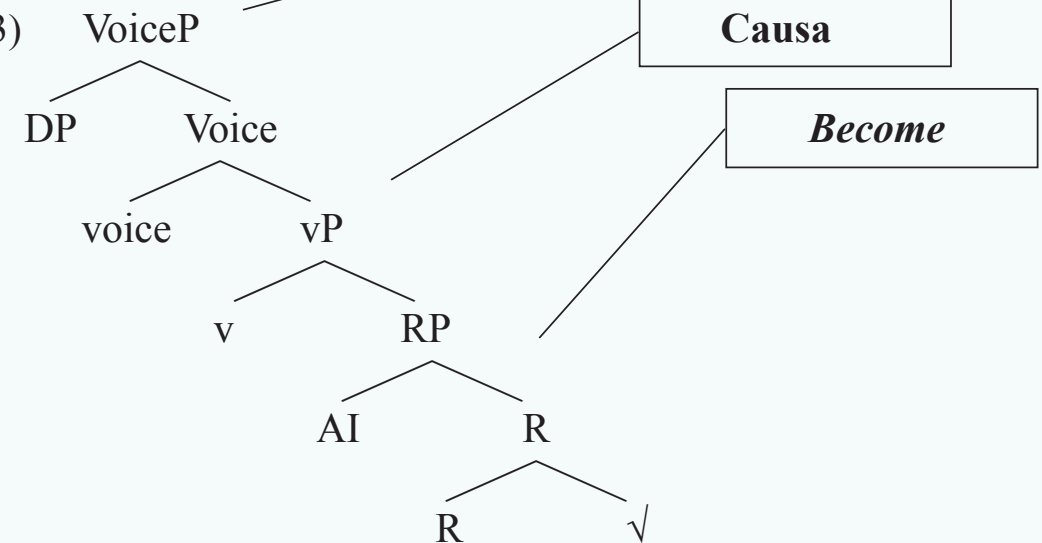

Esses elementos nos parecem suficientes e necessários para analisar os tipos de eventos identificados (1. Incoativo; 2. Estritamente causativo; 3. Causativo subespecificado para [ag]; 4. Totalmente subespecificado; 5. Causativo agentivo estrito; 6. Causativo estrito com Voice) quando investigamos a estrutura dos dados com base nos segunintes testes (a-d):

Tabela 4 - Comportamento frente aos testes para identificação de tipos de eventos

\begin{tabular}{|c|c|c|c|c|c|c|}
\hline & \multicolumn{6}{|c|}{ Tipos de eventos de mudança de estado } \\
\hline & 1.Incoativo & $\begin{array}{c}\text { 2.Causativo } \\
\text { estrito }\end{array}$ & $\begin{array}{l}\text { 3.Causativo } \\
\text { subespeci- } \\
\text { ficado para } \\
\text { [ag] }\end{array}$ & $\begin{array}{l}\text { 4.Totalmen- } \\
\text { te subespe- } \\
\text { cificado }\end{array}$ & $\begin{array}{l}\text { 5.Causativo } \\
\text { agentivo } \\
\text { estrito }\end{array}$ & $\begin{array}{l}\text { 6.Causativo } \\
\text { estrito com } \\
\text { Voice }\end{array}$ \\
\hline $\begin{array}{l}\text { Especifi- } \\
\text { cação dos } \\
\text { traços }\end{array}$ & \multirow{2}{*}{$\begin{array}{c}\sqrt{ } / \mathrm{RP}[+\mathrm{int}] \\
v_{\text {[-voice] }}\end{array}$} & \multirow{2}{*}{$\begin{array}{c}\sqrt{ } / \mathrm{RP}[\text {-int }] \\
v_{\text {[-voice] }}\end{array}$} & \multirow{2}{*}{$\begin{array}{c}\sqrt{ } / \mathrm{RP}[\text {-int }] \\
v_{[+ \text {voice }]} \\
\text { Voice }[ \pm \mathrm{ag}]\end{array}$} & \multirow{2}{*}{$\begin{array}{c}\sqrt{ } / \mathrm{RP}[ \pm \text { int }] \\
v_{[}^{ \pm}{ }_{\text {voice }} \\
\text { Voice }[ \pm \text { ag }]\end{array}$} & \multirow{2}{*}{$\begin{array}{c}\sqrt{ } / \mathrm{RP}[\text {-int }] \\
v_{\text {[+voice] }} \\
\text { Voice }[+ \text { ag }]\end{array}$} & \multirow{2}{*}{$\begin{array}{c}\sqrt{ } / \mathrm{RP}[-\mathrm{int}] \\
v_{\text {[+voice }]} \\
\text { Voice }[-\mathrm{ag}]\end{array}$} \\
\hline Testes & & & & & & \\
\hline $\begin{array}{l}\text { a. Transitiva } \\
\text { com agente }\end{array}$ & $* \#^{4}$ & *\# & ok & ok & ok & *\# \\
\hline $\begin{array}{l}\text { b. Transitiva } \\
\text { com causa }\end{array}$ & ok & ok & ok & ok & $*$ & ok \\
\hline $\begin{array}{l}\text { c. Intransi- } \\
\text { tiva }\end{array}$ & $\mathrm{ok}^{5}$ & $\mathrm{ok}^{6}$ & $*$ & ok & $*$ & $\mathrm{ok}^{6}$ \\
\hline d. Passiva & $*$ & $*$ & ok & ok & ok & ok \\
\hline Exemplo & amadurecer & enfurecer & embelezar & amolecer & abastecer & enobrecer \\
\hline
\end{tabular}

4. O sinal *\# indica que o AE animado da sentença não é interpretado como agente direto do evento de mudança de estado do argumento interno. Por exemplo, na sentença "O filho enfureceu a mãe", o filho faz algo que causa o enfurecimento da mãe. 
A gramaticalidade no teste a. revela que o verbo pode ocorrer em uma estrutura transitiva com $\mathrm{AE}$ interpretado como agente; $o$ teste $\mathrm{b}$. revela que o verbo pode ocorrer em uma estrutura transitiva com $\mathrm{AE}$ não agentivo, sob o rótulo geral causa; o teste em c. revela que o verbo pode ocorrer em uma estrutura intransitiva em que há ausência do $\mathrm{AE}$ e presença de argumento interno alçado para posição de sujeito 7 . A presença do clítico se em estruturas intransitivas é proibida para alguns verbos e opcional para outros. Optamos por não considerar rigidamente o teste com se porque seu uso está em mudança e é sensível à variação dialetal, mas observamos que a possibilidade de ocorrer opocionalmente com esse clítico é a única característica que diferencia, por exemplo, eventos estritamente causativos de incoativos. Em vez de conclusões sobre essa possibilidade, teceremos observações empíricas que podem contribuir para a literatura. $\mathrm{O}$ teste $\mathrm{d}$. consiste no uso do verbo na voz passiva. Como a passiva é fortemente relacionada à possibilidade de um verbo aceitar um $\mathrm{AE}$, esse teste diferencia estruturas que aceitam um $\mathrm{AE}$ direto, ou verdadeiro, daqueles verbos que são inicialmente incoativos e aceitam somente causas como AEs, como detalharemos adiante. A passiva também diferencia dois tipos de formações que admitem somente uma causa como AE. Alguns verbos que permitem somente causa permitem também a formação passiva, o que nos faz pensar que tais verbos contêm uma projeção de Voice em sua versão transitiva.

Dado nosso interesse no estudo da correlação entre morfologia e estrutura argumental, nosso objetivo é observar se a forma do verbo pode revelar propensão à formação de determinado tipo de evento. Alguns exemplos prototípicos frente aos testes acolhidos e a totalidade dos dados classificados estão dispostos no Anexo 1. A totalidade dos testes está disposta em Bassani (2013). Para fins de clareza, a ordem de apresentação das classes é: 4, 3, 1, 2, 6 e 5.

\subsection{Tipo 4. Totalmente subespecificado}

Uma subclasse dos VMEs denota uma mudança de estado do argumento interno que pode ser desencadeada por força externa subespecificada, ou seja, pode ser de tipo agente, instrumento ou causa/eventualidade:

(14) O João/o vento/o furacão/uma pedra quebrou o galho da árvore.

(15) O galho da árvore quebrou.

Segundo $\mathrm{CG}$, as seguintes propriedades sintáticas são particulares a essa classe: possibilidade de passivização, uso opcional do clítico se (17) e

7. Nos verbos alternantes incoativos e estritamente causativos, o argumento interno pode permanecer in situ. Esse é um fator que diferencia, por exemplo, sentenças intransitivas inacusativas e incoativas de sentenças intransitivas absolutas, termo sugerido por Negrão e Vioti (2010:38). Carvalho (2016), no entanto, revela que dados de sentenças absolutas podem ocorrer na ordem Verbo-Sujeito. Por razões de espaço, não detalharemos essa discussão. 
indeterminação do sujeito (18). A alternância é resultado da possibilidade de expressão da porção mais encaixada do evento descrito por [[X (ACT)] CAUSE [Y BECOME < STATE $>$ ]; no entanto, em uma abordagem da Semântica Lexical, a Estrutura Lexical Conceitual implica que CAUSE está lexicalmente codificada nesses verbos. As versões intransitivas seriam resultado de um processo de anti/decausativização.

(16) O galho da árvore foi quebrado.

(17) O galho da árvore (se) quebrou.

(18) Quebraram o galho da árvore.

Alexiadou, Anagnostopoulou e Schäfer (2006) defendem que a noção de causa está presente mesmo nessas versões intransitivas, chamadas pelos autores de anticausativas. A distribuição dos PPs nas sentenças passivas e anticausativas traz evidência de que o componente Causa está presente em ambas as realizações dessas raízes, mas o componente agentividade só está disponível para as passivas: na forma passiva, PPs que introduzem agentes, causas e instrumentos são licenciados. Vejamos que os mesmos papeis semânticos atribuídos ao $\mathrm{AE}$ (agente ou causa) estão disponíveis para esses PPs:

(19) O galho da árvore foi quebrado pelo João/ pelo vento/furacão/?pela pedra.

No entanto, nas anticausativas, somente causas são licenciadas por PPs. No caso do PB, a preposição com é selecionada para introduzir tal causa, mas, como previsto, não permite a introdução de um instrumento:

(20) O galho da árvore quebrou *pelo, *com o João / *pela, *com a pedra/ *pelo, com o vento/furacão.

$\mathrm{Na}$ análise, os autores sugerem que tais verbos sejam decompostos em uma estrutura com três camadas: Voice, $v \mathrm{P}$ e um componente que inclui a raiz. Nessa estrutura, Voice introduz o AE e pode carregar traços relacionados à agentividade. Além disso, também pode abrigar a morfologia não ativa de certas línguas, como o grego. A morfologia não ativa é tomada como reflexo morfológico do fato de Voice não apresentar AE explícito (uma das ocorrências do clítico se/si das línguas românicas é considerada uma manifestação desse tipo de morfologia). O núcleo $v$ introduz uma relação causal entre o evento causador e o estado resultante denotado pelo seu complemento. Preposições relacionadas ao agente e instrumentos são licenciadas por Voice e preposições relacionadas a causa/causadores são licenciadas por $v$. A seguinte estrutura seria nuclear em causativas, anticausativas e passivas: 
(21) VoiceP

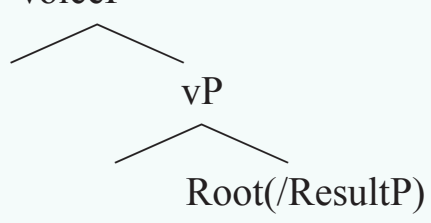

Com a ideia de que as versões anticausativas apresentam o componente CAUSA, revelado pela modificação, conseguimos apreender a ideia de CG de que "CAUSE está lexicalmente codificada" em uma análise estrutural, na qual a alternância não precisa ser não direcionada.

Para maior clareza de exposição, representamos abaixo a nossa proposta para as versões transitiva e intransitiva da raiz $\sqrt{ }$ QUEBR-. Assumimos que essa raiz é subespecificada por poder ser conceitualizada como o resultado de um evento interna ou externamente causado, propriedade que representamos pelo traço [int]. Ainda, essa estrutura é dada como totalmente subespecificada porque, quando o núcleo Voice é projetado, seu traço pode ser especificado tanto como [ $+\mathrm{ag}]$, quanto como [-ag]. Aqui reside uma diferença entre nossa análise e a de CG: acreditamos que um evento como o de quebrar, cujo uso alternante é difundido e generalizado no $\mathrm{PB}$, não precisa ser considerado como inicialmente causativo.

(22) O João/vento quebrou o galho.

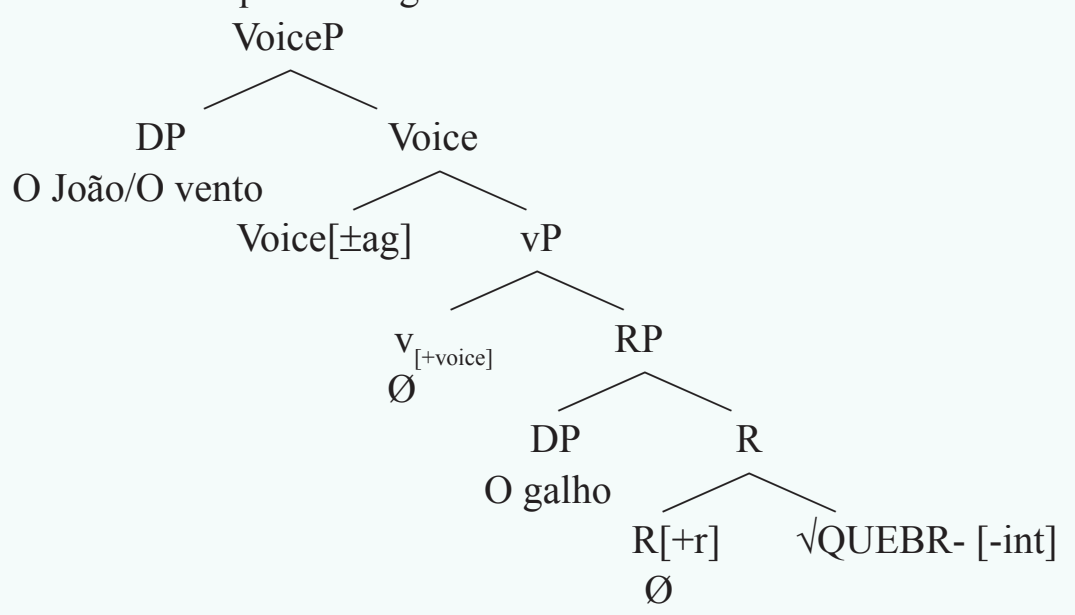

(23) O galho quebrou.

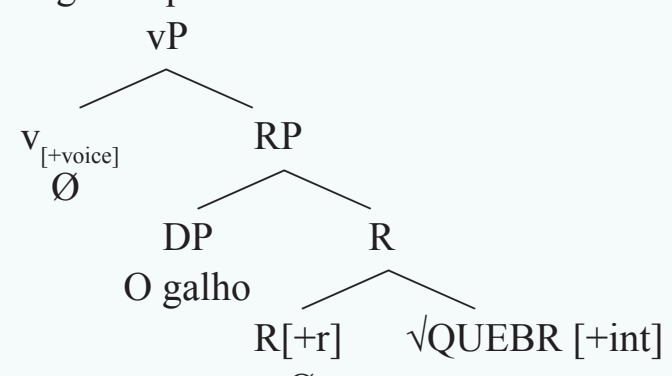

$\varnothing$ 
O núcleo $v$ nas estruturas é o mesmo, diferentemente do que se sugere em Harley (2007), em que dois tipos de v (Become e Cause) são propostos. A diferença está em que, em (23), o núcleo Voice não é projetado, mas poderia ser, e esse é um ponto crucial que diferencia esse tipo de verbo dos incoativos, como veremos. Alguns verbos classificados como totalmente subespecificados dentro da classe de VMEs são: encher, acalmar, esvaziar, alisar, amolecer, entortar, acovardar, encrespar, etc.

Observando nossos dados, alguns achados importantes surgem com relação à marcação morfológica no sentido de apontar contraexemplos ao que a literatura tem dito sobre verbos com sufixo -ec-, principalmente. Para que houvesse uma relação estrita entre o sufixo -ec- e os VMEs internamente causada, como afirma Oliveira (2009), a ocorrência desse sufixo deveria se restringir a estruturas intransitivas incoativas (tipo 1), como as que iremos explorar em seguida, e assumiríamos que a presença desse afixo pudesse corroborar a existência de um $v$ especializado de "sabor" BECOME. No entanto, não é o que se verifica. O sufixo -ec- também ocorre em estruturas totalmente subespecificadas (tipo $4)$, em outros termos, em estruturas com raízes [ \pm int], e em verbos em que o evento necessariamente é concebido como fruto de força externa [-int], de tipo estritamente causativo (tipos 2 e 4) ou agentivo (tipo 5). Primeiramente, vejamos o exemplo com o verbo amolecer.

(24) Amolecer

a. A esteticista amoleceu a cera (com uma colher de pau).

b. O calor amoleceu a cera.

c. A cera (?se) amoleceu.

d. A cera foi amolecida (pela esteticista/pelo calor).

$\mathrm{O}$ evento denotado por amolecer pode ser interpretado como um evento desencadeado por força externa ou interna, do mesmo modo que ocorre com o verbo quebrar, e a raiz $\sqrt{ }$ MOL- pode ocorrer em uma estrutura com um Voice de tipo [+ag] ou [-ag]. Como vemos nos dados acima, essa raiz ocorre em sentenças transitivas com a presença de um agente evidenciado pelo instrumento controlado licenciado no PP em (24)a, aceita uma causa, como em (24)b, e ainda pode ser licenciada na versão intransitiva. Esses testes revelam que o agente é um agente direto do evento denotado pela raiz. A estrutura em (25) representa a versão com $\mathrm{AE}$ agente: 
(25) A esteticista amoleceu a cera (com uma colher de pau).

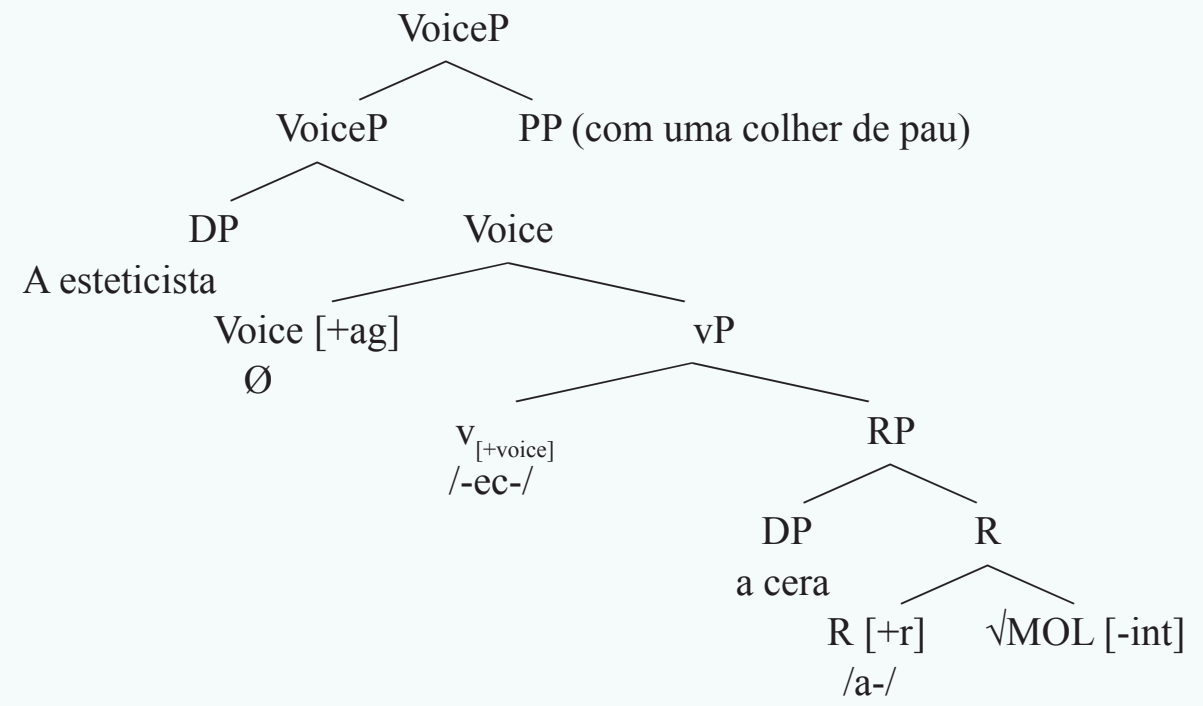

A possibilidade de indeterminação do sujeito (em "Amoleceram a cera") é explicada pela presença de um núcleo de Voice $[+a g]$ que tem na sua posição de especificador um pro. Pro está, obviamente, em distribuição complementar com a realização de um DP referencial porque só existe uma posição estrutural em que um elemento nominal pode ser interpretado como um agente, essa posição é spec, VoiceP [+ag].

Desse modo, ao testar nossos dados, notamos que a gramaticalidade em sentenças transitivas com agente (direto), sentenças transitivas com causa, sentenças intransitivas com argumento interno e sentenças passivas revela que uma raiz é completamente subespecificada. Os testes de passivização e indeterminação do sujeito, citados acima, são redundantes, pois revelam a presença de um núcleo Voice e traços de agentividade, e por isso só aplicamos o primeiro à totalidade dos dados.

\subsection{Tipo 3. Causativos subespecificados para [ag]}

Um outro tipo de subespecificação se dá somente no domínio do papel semântico do AE. São eventos em que a mudança de estado deve ser necessariamente desencadeada por força externa, pelo que são eventos causativos, mas essa força pode ser tanto um agente quanto uma causa desencadeadora. Em outras palavras, o domínio $v \mathrm{P}$ (que inclui necessariamente $v[+$ voice] $)$ não impõe restrições ao tipo de AE que será projetado em especificador de Voice. Como vemos nos exemplos abaixo, por serem concebidos como fruto de força externa, tais verbos não participam de alternâncias incoativas e permitem a formação passiva. Alguns verbos pertencentes a esse tipo são: arriscar, assegurar, aprimorar, entorpecer, embelezar, encobertar, endireitar, anular, etc. 
(26) Anular
a. O professor anulou a prova.
b. A desonestidade dos alunos anulou a prova.
c. A prova (*se) anulou (*sozinha).
d. A prova foi anulada (pelo professor).

Aqui surge uma questão crucial em relação ao $\mathrm{AE}$ de tipo causa, mas para nos dedicarmos a ela, precisamos, antes de tudo, apresentar a discussão sobre as estruturas de eventos de tipo 1.

\subsection{Tipo 1. Incoativos}

Os ditos VMEs incoativos, cuja representação de CG é ([X] CAUSE) [Y BECOME $<$ STATE $>$ ], denotam uma mudança que depende de propriedades internas ao argumento interno. Como já destacamos, diversos trabalhos denominam-nos de VMEs internamente causada.

Tais verbos não permitem que um DP animado em sua posição de especificador seja interpretado como um agente direto do evento de mudança codificado pela raiz verbal. Essa impossibilidade de codificação de agentividade direta é revelada por três propriedades sintáticas no PB: a) não aceitam passivização; b) não aceitam indeterminação do sujeito; c) não aceitam inserção do clítico se:

(27) *A banana foi amadurecida.

(28) *Amadureceram a banana.

(29) *A banana se amadureceu.

Segundo CG, a subparte opcional ([X] CAUSE) representa o fato de que tais verbos parecem aceitar uma causa indireta como $\mathrm{AE}$, tal como na seguinte sentença, mas não se assume que essa causa esteja lexicalmente codificada:

(30) O calor amadureceu a banana.

As autoras afirmam que o fato de não aceitarem a marca se indica que esses verbos não têm em sua estrutura semântica o predicado CAUSE, ao passo que verbos causativos apresentam esse primitivo em sua estrutura semântica e, ao serem incoativizados, perdem esse predicado, o que resulta na marcação morfológica.

Alexiadou (2014:4), a partir de dados expostos em outros trabalhos, apresenta classs de verbos em inglês e em grego, que nos parecem ter as mesmas proporiedades, como nos exemplos abaixo, e questiona o porquê de somente AEs de tipo Causa serem permitidos. 
(31) Inglês

a. Early summer heat blossomed fruit trees across the valley.

'O calor do início do verão floresceu as árvores frutíferas em todo o vale'

b. Salt air and other pollutants can decay prints.

'Maresia e outros poluentes podem corroer pinturas.'

(32) Grego
a. O thalasinos areas skuriase to frahti.
The sea air rustes-3SG the fence
'The sea air rusted the fence' ('A maresia enferrujou a cerca')
b. I poli zahari sapizi ta dondia.
The much sugar rot-3sg the teeth
'A lot of sugar rots the teeth' ('Muito açúcar apodrece os dentes')

A autora sugere que tal argumento (nunca agentivo) é licenciado diretamente por $v$. A ideia é que os sujeitos de verbos com raiz internamente causada são realizações alternativas de PPs causa, ou seja, semanticamente, eles são tipos de modificadores de evento mais do que sujeitos verdadeiros, o que deve se traduzir na estrutura de algum modo. A análise estrutural propõe que esses elementos contêm, inicialmente, apenas $v$ e a camada de resultado, como em (33). Opcionalmente, um AE [-ag] pode ser licenciado por $v$ (34). Traduzindo essa ideia para a nossa proposta de que há, estruturalmente, dois tipos de verbalizadores $\left(v_{[+ \text {voice }]}\right.$ e $\left.v_{[- \text {-voice }]}\right)$, temos que $v_{[+ \text {voice }]}$ é capaz de licenciar um $\mathrm{AE}$ em sua posição de especificador. A discussão se fará mais clara na continuação desta subseção.

(33)

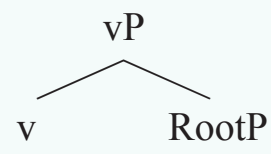

(34)

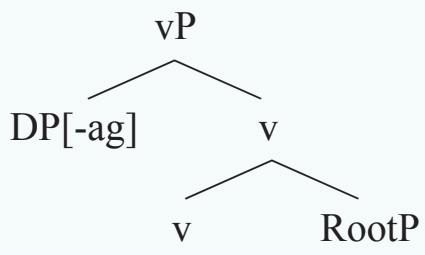

A evidência empírica para o fato de que tais verbos não apresentam AE projetado em spec, VoiceP é a impossibilidade de tais verbos sofrerem passivização.

(35) * A banana foi amadurecida pela cozinheira/ pelo calor. 
À luz desses fatos, podemos retomar a questão de AEs de tipo causa [-ag], que aparentemente são licenciados em estruturas com $v_{[+ \text {voice }}$ : seriam tais argumentos introduzidos diretamente por $v \mathrm{P}$, da mesma forma como são introduzidos os PPs de tipo causa em estruturas anticausativas/incoativas (como veremos a seguir), ou seriam introduzidos do mesmo modo como são introduzidos os agentes, em spec, VoiceP?

A estrutura passiva parece ser um importante teste para responder a essa questão. Ambos os AEs de tipo causa ou agente podem ser opcionalmente licenciados em PPs adjuntos nas estruturas passivas de verbos com raízes subespecificadas (36). Isso parece indicar que ambos os tipos semânticos de argumentos têm o mesmo estatuto sintático. Nas versões transitivas, Voice licenciaria causas e agentes na posição de especificador. Na versão passiva, seguindo a linha de Schäfer (2008), um núcleo Voice passivo licenciaria ambos os PPs, agentes e causas ${ }^{8}$. Na versão intransitiva, pela ausência de Voice, apenas causas são licenciadas, em spec, $v \mathrm{P}$ (37). Lembramos que apenas Voice pode licenciar traços relacionados à agentividade (Alexiadou; Anagnostopoulou; Schäfer 2006).

(36) A cera foi amolecida pela esteticista/pelo calor.

(37) A cera amoleceu *pela/*com a esteticista/ com o calor.

Ao observar a morfologia dos VMEs incoativos de causa interna (tipo 1) cujo comportamento estrutural será exemplificado por apodrecer, notamos que há grande ocorrência do sufixo -ec-. Outros verbos com esse comportamento são: amanhecer ${ }^{9}$, emagrecer, engravidar, envelhecer, endurecer, engordar, anoitecer, esverdear.

(38) Apodrecer
a. *\# O lenhador apodreceu a madeira.
b. A umidade apodreceu a madeira.
c. A madeira apodreceu.
d. *A madeira se aprodreceu.
e. *A madeira foi apodrecida (pelo lenhador/pela umidade).
f. *Apodreceram a madeira.

Em (38), o AE da sentença transitiva só pode ser interpretado como um facilitador, e não como um agente do evento expresso pela raiz do verbo, o que representamos pela junção dos sinais *\#, (O lenhador deixou a madeira exposta à umidade, o que de fato causou o seu apodrecimento). Uma causa é

8. Para estrutura das passivas, cf.: Schäfer (2008).

9. Amanhecer e anoitecer são ainda mais restritivos, pois apenas aceitam AE em um "contexto poético" (termo citado pelos falantes): "O sol amanheceu o dia"/ "A lua anoiteceu o dia". Um dos pareceristas anônimos indicou que esses verbos também aceitam AEs introduzidos como adjuntos em alguns contextos, tais como em "Eu amanheci com dor de cabeça". 
permitada na posição de sujeito, como em b., e a realização mais natural para esse verbo é aquela em c., na forma de uma sentença intransitiva. O verbo não se realiza normalmente em sentenças passivas (38)d., com o clítico se (38)e. e com a indeterminação do sujeito (38)f.. Nesses casos, com relação à presença de -ec-e o tipo de complemento tomado por $v$, notamos que esses verbos tomam preferencialmente raízes simples. Tal fato morfológico está diretamente correlacionado ao tipo semântico [+int] dessa raiz: a raiz não precisa sofrer nenhum tipo de manipulação morfológica para denotar um estado.

$\mathrm{Na}$ estrutura monoargumental e incoativa abaixo, o núcleo $\mathrm{R}[+\mathrm{r}]$ licencia estruturalmente um argumento interno e o relaciona à raiz de estado; o DP recebe sua interpretação semântica em spec, R. Há, então, um tipo de small clause que contém um estado cuja combinação (como complemento) com um núcleo $v$ eventivo gera interpretação de um evento de mudança e resultado. A ordem Sujeito-Verbo (SV) é derivada pelo movimento do argumento interno para especificador de TP para checagem de caso nominativo, pois o $v$ inacusativo não é capaz de checar caso acusativo do argumento interno porque não licencia uma projeção de Voice $^{10}$.

(39) A madeira apodreceu.

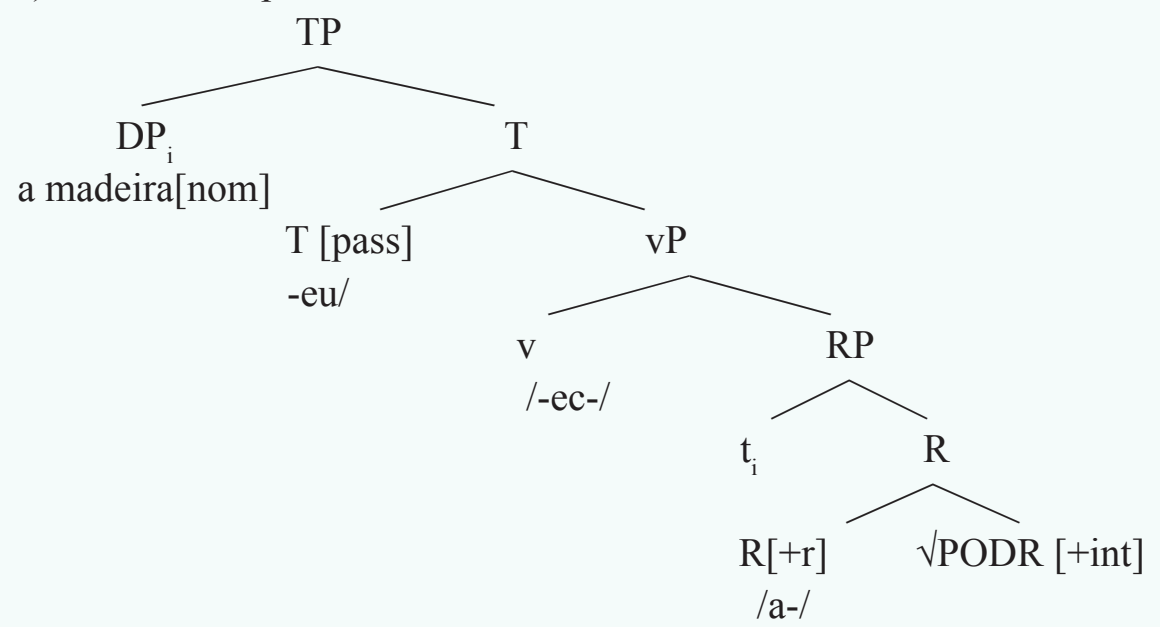

Nessa estrutura, o núcleo Voice não é licenciado e, por isso, não é possível ter formas intransitivas como a passiva e a indeterminação porque essas são todas estruturas dependentes desse núcleo.

A estrutura sugerida acima se parece com a de verbos inacusativos prototípicos, como nascer e morrer. No entanto, existe uma diferença: verbos como amadurecer e apodrecer podem apresentar versões transitivas (40) ao passo que aqueles não podem (41):

10. Verbos que não projetam $\mathrm{AE}$ não atribuem caso acusativo (Burzio, 1986). 
(40) a. A cozinheira amadureceu a banana (no forno).

b. O calor amadureceu a banana.

(41) a. * O médico nasceu o bebê (no fórceps).

b. * O parto normal $/ *$ A cesariana/ $* \mathrm{O}$ fórceps nasceu o bebê.

Por isso, apesar de não nos determos na estrutura de verbos inacusativos prototípicos, como nascer e morrer, assumimos que sua estrutura deve ser diferente da dos verbos como amadurecer e apodrecer.

Antes de propor tal análise, uma primeira hipótese levantada foi a de que o fato de um AE humano e animado somente poder ser interpretado como um facilitador para essa classe de raízes (amadurecer, apodrecer) se dá porque ele é, na verdade, um agente de um outro evento mais externo, que não aquele relacionado à raiz de estado interno. Retomando o exemplo de apodrecer, em uma sentença como o lenhador apodreceu a madeira, o AE agente só pode causar de modo indireto o apodrecimento do argumento interno, por meio de um outro evento. Ou seja, ele pode, por exemplo, fazer a madeira apodrecer deixando-a exposta à umidade, o que implica um tipo de causação indireta. Nesse caso, em MD, uma maneira de representar estruturalmente essa relação se faz por meio de dois núcleos introdutores de eventos, dois vs: um que toma a camada que inclui a raiz como complemento e um que toma um outro $v \mathrm{P}$ como complemento. Esse tipo de estrutura já foi sugerida por Harley (2008) para o que a autora denomina de causativos sintáticos do japonês, em oposição a causativos lexicais, que têm o causador licenciado diretamente pelo $v$ mais baixo. A paráfrase ideal para esses casos é aquela que inclui o verbo fazer: $O$ lenhador fez a madeira apodrecer.

No que se refere a AEs de tipo causa, a observação dos dados nos permite concluir que muitas vezes essas causas são expressas por nomes eventivos. Por exemplo, em (42), a chuva é claramente um evento que causa o evento incoativo de apodrecer. Em (43), o nome eventivo (discurso) é compatível inclusive com a presença de um agente introduzido por uma preposição (do político).

(42) A chuva apodreceu as plantas.

(43) O discurso (do político) enfureceu o público.

Em vários casos, AEs do tipo causa em sentenças transitivas podem configurar, na verdade, eventos causadores. Alguns deles estão dispostos a seguir:

(44) O descuido adoeceu o menino.

(45) (Assistir a) Os programas de TV emburreceram o telespectador.

(46) A lavagem enrijeceu a sapatilha. 
Não iremos detalhar a estrutura de tais nomes eventivos, pois fugiria ao nosso escopo, mas, ainda dentro dessa hipótese, poder-se-ia sugerir uma estrutura de eventos com dois núcleos, bem próxima à de (47) a seguir.

(47) $\mathrm{O}(\mathrm{s})$ lenhador(es) apodreceu(ram) a madeira.

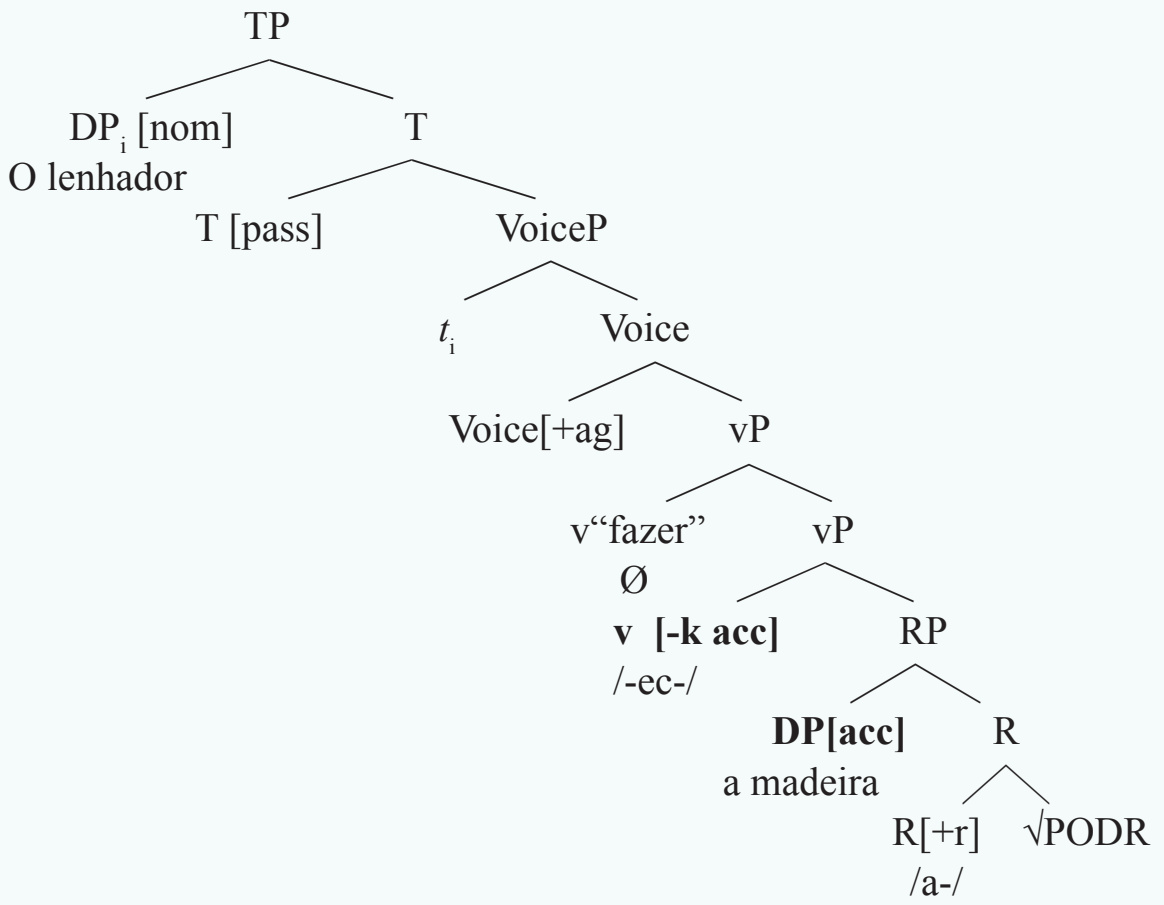

Por hipótese, se considerarmos que o $v$ presente nessas formações é um $v$ que não licencia seu $\mathrm{AE}$, devemos ter como consequência o fato de que esse $v$ não pode atribuir caso acusativo ao seu argumento interno. Contrariamente, nesses dados, o argumento interno recebe caso acusativo. A atribuição de caso nessas versões transitivas dos verbos incoativos mostra que elas se comportam sintaticamente como sentenças monoracionais e não como sentenças bioracionais, como sentenças de causa indireta.

Por isso, parece-nos mais apropriado descartar essa hipótese e assumir que AEs com raízes de estado interno (causa e NP animado não agentivo) são licenciados diretamente por $v$, e não por Voice e nem por um outro $v$ mais externo. $\mathrm{O}$ único núcleo $v$ presente atribui caso acusativo ao argumento interno nesses casos porque possui uma projeção de $\mathrm{AE}$ associada a ele. Nesse sentido, temos um tipo estrutural de $v$ diferente daquele que ocorre em eventos externamente causados. Tivemos de assumir, então, dois tipos de verbalizadores para abarcar nossos dados: um que se combina (opcionalmente) com Voice e um que nunca se combina com Voice. O primeiro tipo está presente em eventos externamente causados e o segundo segundo tipo em eventos internamente causados; esses licenciam opcionalmente uma posição de especificador com traços [-ag]. A estrutura abaixo representa o segundo tipo de verbalizador. 
(48)

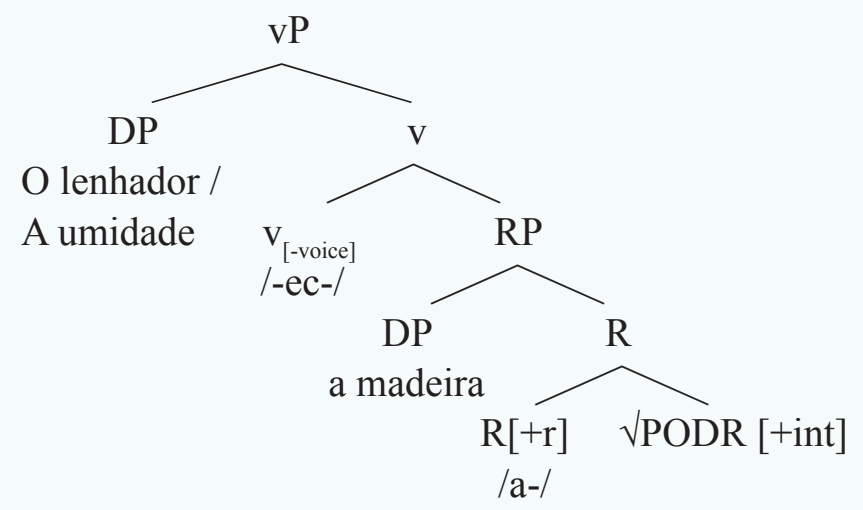

Uma evidência para a estrutura sugerida em (48) surge da modificação pelo advérbio quase. Quando adicionamos quase a uma sentença que descreve um evento internamente causado, mesmo que exista um sujeito (animado ou não), não é possível apreender a leitura em que o advérbio tem escopo sobre todo o evento, incluindo o AE: isso se dá porque não há Voice. A leitura disponível é a de modificação da camada de resultado.

(49) A umidade quase apodreceu a madeira.

Int1: \#A umidade quase desencadeou o processo de apodrecimento. Int2: A madeira quase ficou podre.

(50) O calor quase amadureceu a fruta.

Int1: \#O calor quase desencadeou o processo de amadurecimento.

Int2: A fruta quase ficou madura.

Gostaríamos de acrescentar uma reflexão acerca da tipologia das raízes. Apesar de as classificarmos a priori, nos parece que em alguns casos é o argumento interno que valora a especificação da raiz. Por exemplo, é consenso na literatura que amadurecer denota uma mudança de estado internamente causada. Contudo, se pensarmos no $v \mathrm{P}$ [amadurecer a Maria], em que o argumento interno é humano e animado, fica difícil considerar que a mudança é conceitualizada como internamente causada. $\mathrm{O}$ mesmo se dá para algo como o $v$ P[amadurecer o vinho]. Pode-se dizer que esses são usos metafóricos, mas essa não é uma explicação satisfatória, dado que esse uso metafórico, especificamente, é derivado da combinação estrutural com um tipo diferente de argumento interno, ou seja, da manipulação da estrutura sintática desse "verbo", e aspectos robustos do significado nuclear e das características morfológicas da raiz são preservados, de modo que é improvável que sejam dois verbos homônimos. Isso se comprova, por exemplo, pelo fato de podermos formar uma passiva com essas combinações. Assim, a especificação do tipo de mudança é também uma característica composicional com base no sintagma RP do que somente um traço ou propriedade exclusiva da raiz. 
(51) "Este vinho foi amadurecido em barris de carvalho por seis meses."

(52) "Mas aos poucos a ideia foi se amadurecendo e a ansiedade aumentando ${ }^{12}$.

\subsection{Tipo 2. Estritamente Causativos}

Observando um novo tipo de comportamento, identificamos uma parte de nossos dados com os verbos chamados por CG de estritamente causativos (rótulo que adotamos) exemplificados por preocupar e representados por [[X] CAUSE [Y BECOME $<$ STATE $>$ ]].

Esse tipo de verbo aceita somente uma causa como $\mathrm{AE}$ e são de tipo psicológico com objeto experienciador. Se assemelham aos incoativos por não aceitarem a passivização (53), mas se distinguem por aceitarem opcionalmente o clítico se na versão intransitiva (54) ${ }^{13}$. A Estrutura Lexical Conceitual sugerida pelas autoras prevê o componente causa como obrigatório, diferentemente da sugerida para verbos incoativos.

(53) *A mãe foi preocupada pelo filho.

(54) A mãe (se) preocupou com o filho.

Os verbos pertencentes a essa classe são: apaixonar, enriquecer, estremecer, entristecer, empobrecer, enfurecer, emudecer, etc, cujo comportamento está exemplificado em (55).

(55) Enfurecer
a. *\#O filho enfureceu/entristeceu a mãe.
b. A confusão enfureceu/entristeceu a mãe.
c. A mãe (se) enfureceu/entristeceu.
d. *A mãe foi enfurecida/entristecida (pelo filho). ${ }^{14}$

Assim como nos verbos com mudança internamente causada, o verbo enfurecer aceita um PP adjunto com o argumento de tipo causa, mas não é compatível com a formação passiva. Por isso, em nossa análise, os argumentos desses verbos devem ser projetados diretamente como especificadores de $v_{[- \text {-voice] }}$, assemelhando-se aos verbos incoativos. Temos uma explicação uniforme e estruturada, então, para a atribuição do papel semântico do AE: por estar na posição de especificador de $v_{\text {[-voice], }}$ o $\mathrm{AE}$ não é capaz de ser interpretado como $[+\mathrm{ag}]$.

11. http://www.poraodovinho.com.br/nacionais.php

12. http://www.pj.org.br/jmj/ja-fui/

13. No dialeto paulistano, a presença do clítico é muito frequente com os verbos desta classe, o que se nota pela agramaticalidade atribuída a alguns exemplos, como em O João *(se) enervou.

14. Nesse caso, o falante prefere usar a passiva com ficar, de estado resultante: A mãe ficou enfurecida com o filho. 
(56) a. A mãe se enfureceu com (a atitude de) o filho.

b. *A mãe foi enfurecida pela atitude do filho.

Além disso, apesar de a maior parte desses verbos poder ser de fato identificada como verbos psicológicos com objeto experienciador, notamos que a classe dos causativos estritos não se limita a esse tipo semântico: verbos como enriquecer, emudecer, afamar não apresentam mudança de estado psicológico e têm comportamento estrutural compatível com o dessa classe.

Resta-nos discutir porque tais formações ocorrem opcionalmente com o clítico se ao passo que essa morfologia é rejeitada na classe dos verbos incoativos. A diferença essencial entre os dois tipos de raízes está em que, no primeiro caso, as raízes denotam inicialmente estados [+int] (como maduro, podre) e, no segundo os estados, são [-int] (como triste, em estado de fúria), que necessitam obrigatoriamente do desencadeamento de uma causa externa. O clítico seria um reflexo morfológico dessa necessidade da raiz. $\mathrm{O}$ francês se comporta de modo diferente do PB: nessa língua, eventos internamente causados são compatíveis com a ocorrência do clítico si (Schäfer 2008):

(57) L'univers s'agrandit.

O universo está SE aumentando.

(58) Le temps s'améliore.

O tempo está SE melhorando.

\subsection{Tipo 6. Estritamente causativos com $\boldsymbol{v}_{\text {[+voice] }}$}

Assim como nos eventos de tipo 2 (causativo estrito), em que o DP no especificador de Voice só pode ser [-ag], há também outros casos em que essa restrição se mantêm, mas cujo comportamento não é idêntico ao daquela classe. Tais casos são também denominados aqui de verbos causativos estritos, mas, diferentemente dos verbos como preocupar, enfurecer e entristecer, aceitam a formação passiva. Por isso, os denominamos de causativos estritos com $v_{[+ \text {voice] }}$. Alguns exemplos são: apurar, esquentar, enlouquecer, agravar, engrossar, enfraquecer, envergonhar, esfriar, etc. Obervemos o comportamento exemplar do verbo enferrujar:

(59) Enferrujar
a. *\# O João enferrujou o portão.
b. A maresia enferrujou o portão.
c. O portão (se) enferrujou.
d. O portão foi enferrujado (pela maresia).

\subsection{Tipo 5. Estritamente agentivos}

Outro tipo é identificado em verbos como esclarecer e abastecer, em que a raizé [-int] e Voice especificado como [+ag]. São eventos estritamente agentivos, que rejeitam um DP $[+\mathrm{ag}]$ na posição de argumento externo. Alguns dados 
que apresentam o mesmo comportamento do verbo esclarecer, exemplificado abaixo, são os seguintes: acertar, alinhar, aperfeiçoar, abastecer, aprontar, apropriar, ajeitar, afixar, adoçar, embebedar, apadrinhar, endeusar.

(60) Esclarecer

a. professor esclareceu a questão.

b. *O bilhete esclareceu a questão.

c. A questão *(se) esclareceu.

d. A questão foi esclarecida (pelo professor).

O verbo esclarecer não ocorre na forma incoativa porque pede a expressão de um $\mathrm{AE}$ de tipo agentivo. Mesmo que um $\mathrm{AE}$ não animado seja licenciado, como em b., ele é um produto de um ato agentivo, e parece ser de algum modo controlado. Não são permitidos AEs que denotem forças naturais, por exemplo (compare com "*A chuva esclareceu a questão").

Uma comparação interessante é a do verbo esclarecer com o verbo clarear, que em PB é prototipicamente licenciado em uma estrutura de mudança de estado internamente causada. Desse modo, se assumirmos que a mesma raiz $\sqrt{ }$ CLAR está presente em esclarecer e clarear temos uma explicação para as diferentes interpretações e os comportamentos frente a estrutura argumental, em especial o fato de que clarear permite alternância ao passo que esclarecer não permite. A explicação é estrutural e reside em que, quando na estrutura causativa de esclarecer, o RP em que $\sqrt{ }$ CLAR está incluída é interpretado como externamente causado e Voice é necessariamente [+ag]; já quando na estrutura de clarear, o RP é interpretado como internamente causado, e não há projeção de Voice, como em $O$ céu clareou, por exemplo, ou mesmo em $O$ sol clareou o céu, em que temos um estrutura idêntica àquela sugerida para eventos do tipo de amadurecer (que não se combinam com Voice). Uma possível hipótese de que a agentividade está relacionada à presença dos prefixo es- em esclarecer não se sustenta, dado que outros dados com esse prefixo podem ser interpretados como [+int]: esfriar e esquentar, quando usados em referência ao tempo, por exemplo, não podem ser causativos.

Outro verbo curioso deste grupo é abastecer, cujo comportamento frente aos testes é o exposto em (61) abaixo. O teste de alternância em b. mostra que o verbo ocorre em uma sentença intransitiva, porém é óbvio que a interpretação deve ser agentiva: "o carro abasteceu" implica que alguém desencadeou o evento de abastecer, mas esse argumento não ocorre sintaticamente. Na estrutura sugerida em (62), o núcleo Voice $[+\mathrm{ag}]$ garante a interpretação agentiva e a falta de uma posição de especificador desse núcleo proporciona a alternância intransitiva. Apesar de sintaticamente intransitiva, essa estrutura não é incoativa, pois o traço [int] é [-ag]: 
(61) Abastecer
a. O frentista abasteceu o carro.
b. * A bomba de álcool abasteceu o carro.
c. O carro $(*$ se) abasteceu (*sozinho).
d. O carro foi abastecido (pelo frentista).

(62)

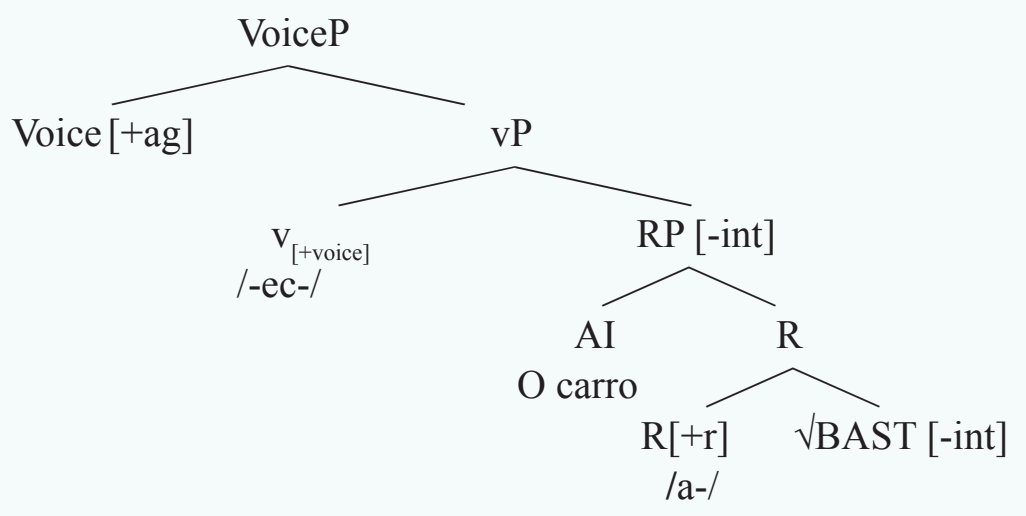

Em princípio, "O carro abasteceu" não deveria ser uma sentença grammatical. No entanto há mais fatores envolvidos: o fato de uma sentença como "Meu carro (já) abasteceu" ser perfeitamente aceitável se deve ao aumento em PB do que Negrão e Viotti (2010:40) denominaram Sentenças Absolutas. As autoras afirmam que, nessas construções:

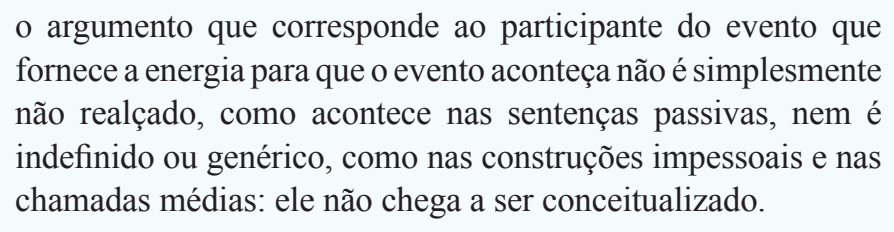

A não conceitualização desse argumento poderia corresponder, em nossos termos, à sua não projeção e, nesse caso, a estrutura seria idêntica à que licencia uma raiz internamente causada. Concordamos com as autoras no aspecto que diz que tais sentenças são diferentes das passivas, impessoais e médias; contudo, discordamos, com base no teste de modificação por advérbios, que não haja nenhuma interpretação de agente ou causa implícita nessas sentenças. Vemos que diferentemente das raízes de tipo internamente causadas (que incluem as subespecificadas), esses verbos não são completamente compatíveis com um advérbio como por si só ou sozinho, que revelaria a completa ausência de força externa. Se o argumento implícito (entendido por nós como a projeção de Voice) não fosse conceitualizado, as sentenças em (65) deveriam ser ótimas: 
(63) A madeira apodreceu sozinha/por si só.

(64) A cera amoleceu sozinha/ por si só.

(65) a. A questão *(se) esclareceu sozinha/ por si só.

b. *O carro abasteceu sozinho/por si só.

Por outro lado, as raízes especificadas como [-int] são compatíveis com advérbios orientados para o $\mathrm{AE}$ agente quando Voice é [+ag]:

(66) \#O lenhador apodreceu a madeira com cuidado/de propósito.

(67) A esteticista amoleceu a cera com cuidado/de propósito.

(68) \# Minha perna amoleceu com cuidado/de propósito.

(69) a. O professor esclareceu a questão com cuidado/de propósito.

b. O frentista abasteceu o carro com cuidado/de propósito.

Contudo, como bem apontam as autoras, a questão não é tão simples. Um argumento que poderia ser usado em favor da ideia da não existência de Voice [+ag] nessas sentenças seria a estranheza da sentença abaixo, que rejeita um advérbio orientado para o $\mathrm{AE}$ agente.

(70) Meu carro abasteceu \# com cuidado/\# de propósito.

Tal advérbio deveria poder se adjungir a VoiceP, se ele de fato existisse nessas sentenças. Talvez a peculiaridade dessas sentenças esteja exatamente no fato de que há uma estrutura intransitiva em que a camada baixa possui uma especificação para externamente causada e, mesmo assim, Voice não é projetado. Essa não é uma questão direta do presente artigo, mas o que tais fatos mostram é que o simples teste de alternância transitivo-intransitiva não é mais um teste efetivo para identificar estruturas incoativas no PB: Meu carro abasteceu é uma alternância intransitiva, mas não é uma estrutura incoativa de alternância como a do verbo amadurecer, por exemplo.

Como já vimos anteriormente, trabalhos como o de Oliveira (2009) propõem oposição entre -iz- como sufixo realizador de $v$ de eventos de mudança de estado externamente causada e -ec- como relativo à mudança de estado internamente causada. Por meio da investigação dos dados acima, mostramos que a segunda afirmação é incorreta, ou pelo menos, deve ser relativizada e colocada em forma de tendência, pois o sufixo -ec- está em todas as possíveis realizações de VMEs.

Apesar de não termos dados numerosos em nosso corpus do sufixo -iz-, faremos uma breve investigação. Em geral, os verbos formados pelo sufixo -iz- também veiculam uma mudança de estado do argumento interno que implica um estado resultante causada por um agente/causa, figurando em estruturas bieventivas, do mesmo modo que se dá com algumas formações em que há ocorrência de -ec-. Alguns testes de negação do resultado (denial 
of result test) abaixo corroboram a existência de mudança de estado e estado resultante.

(71) \#O palhaço aterrorizou as crianças, mas elas não ficaram aterrorizadas.

(72) \# A doceira caramelizou o doce, mas o doce não ficou caramelizado.

Uma primeira diferenciação com relação à realização dos sufixos é que o sufixo -iz- junta-se com mais frequência a estados derivados. Tal fato é exemplificado pelo teste de acarretamento:

(73) A criança ficou \#terror/ aterrorizada.

(74) O açúcar ficou \#caramelo/caramelizado.

O sufixo -iz- combina-se a adjetivos derivados de relação (profissional, americano, familiar), mas esses devem ser reinterpretados como qualificativos, portadores de uma propriedade. Uma forte evidência desse fato é a grande ocorrência de verbos com -iz- formados a partir de adjetivos derivados por -al (formalizar, centralizar, municipalizar) e -vel (responsabilizar, contabilizar, estabilizar). Isso indica que a estrutura em que -iz-ocorre deve conter uma camada que forma um estado derivado a partir da raiz. A estrutura baixa de verbos como profissionalizar e aterrorizar deve ser inicialmente esta a seguir:

(75) Profissionalizar

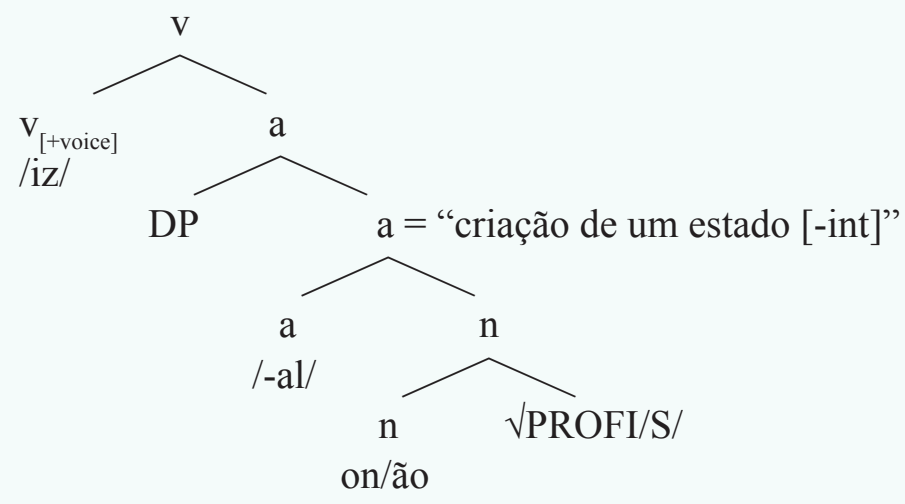

(76) Aterrorizar

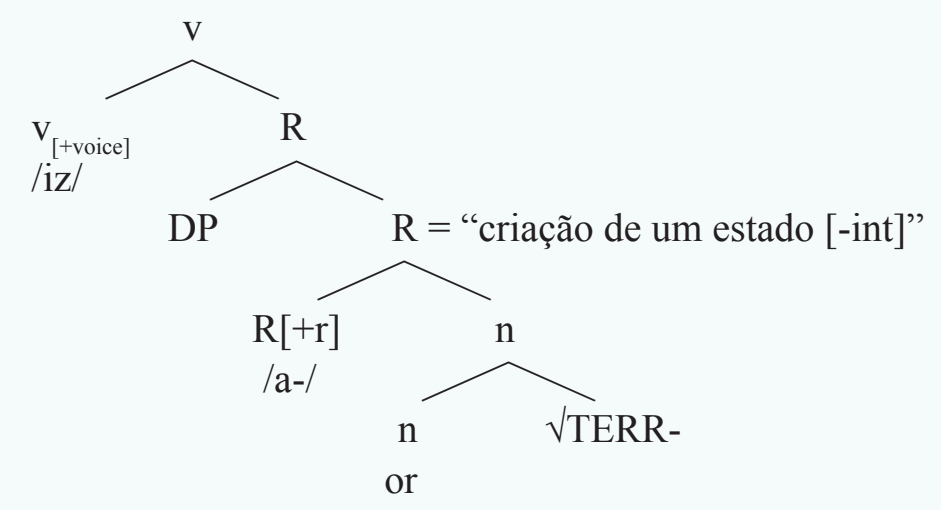


Nas estruturas acima, em verbos com sufixos adjetivais, propomos que o núcleo funcional $a$ é responsável por introduzir o argumento interno e relacionálo ao estado derivado da raiz, que normalmente denota entidades. Já para verbos com prefixos, como aterrorizar, é o núcleo $\mathrm{R}$ que realiza tais funções. Uma evidência relevante é que nas formações com os sufixos -al e -iz-, por exemplo, a presença de prefixos é quase nula ${ }^{15}$.

A pergunta que se segue, na linha de argumentação, é: como se deriva o estado necessário em verbos que contém -iz-, mas não contém realização aberta nem de prefixos e nem se sufixos adjetivais, como é o caso de caramelizar, por exemplo? Observemos a estrutura abaixo:

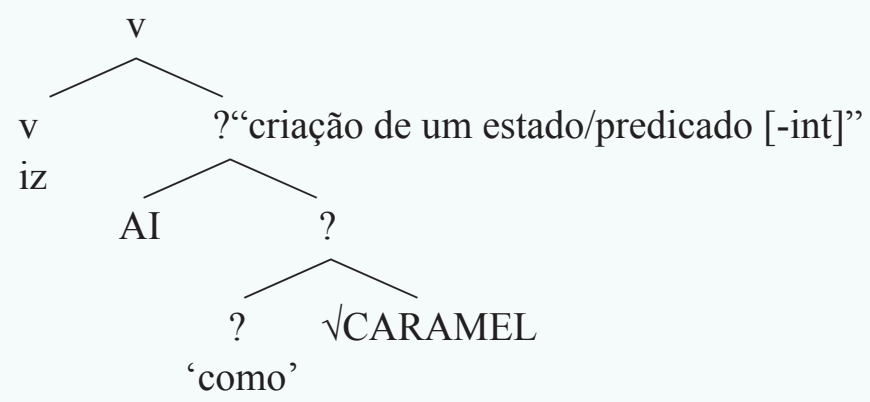

Novamente, tal dado corrobora o abandono de noções categoriais: podemos bem sugerir um rótulo $a$ ou um rótulo $\mathrm{R}$ nesse caso, não há diferença. Diferentemente dos dados acima, em que temos estados derivados, em verbos como amenizar, suavizar e tranquilizar, as raízes (as mesmas presentes em ameno, suave e tranquilo) denotam por elas mesmas estados e são tomadas como complementos de $v$ s realizados por $-i z-$.

Partindo para a realização do $\mathrm{AE}$ em verbos com o sufixo $-i z$, notamos que os estados derivados são em geral interpretados como externamente causados justamente porque as raízes presentes expressam prototipicamente entidades, o que implica sempre a existência de uma projeção de Voice de tipo [ $\left.{ }^{\mathrm{ag}} \mathrm{a}\right]$. Observemos os testes para aterrorizar e caramelizar que revelam que as raízes $\sqrt{T E R R}$ (ou $\sqrt{T E M}$ em atemorizar) e $\sqrt{ }$ CARAMEL ocorrem em sentenças com $\mathrm{AE}$ de tipo agente ou de tipo causa, permitem passivização, uso do clítico se e indeterminação do sujeito. Além disso, como já mostramos, o acarretamento do estado resultante é feito para esses verbos com a forma do particípio. Em geral, esses verbos não alternam normalmente sem a presença do clítico $s e$.

(78) Aterrorizar
a. As vítimas ficaram \#terror/ aterrorizadas.
b. O ladrão aterrorizou as vítimas.
c. A ventania aterrorizou as pessoas.

15. Há algumas formações pouco frequentes listadas em dicionário: assexualizar, assocializar. Com os prefixos $e N$ - e $e S$ - não há registro. 
d. As vítimas *(se) aterrorizaram.

e. As vítimas foram aterrorizadas.

Contudo, contrariando a literatura, alguns dados mostram que o sufixo -iz- pode ocorrer, talvez de modo inovador, em eventos conceitualizados como internamente causados.

(79) Cristalizar
a. *\# A cozinheira cristalizou o mel.
b. A umidade cristalizou o mel.
c. O mel cristalizou.
d. ?? O mel foi cristalizado (pela umidade).

\section{Consideracões finais}

No presente artigo, buscamos investigar as possíveis relações entre morfologia e estrutura argumental em verbos complexos com enfoque para relações entre o tipo semântico da raiz e expressão de causa e argumento externo. Após detalhada observação do comportamento frente a testes estruturais e consequente classificação de verbos complexos, podemos concluir que a morfologia prefixal do PB não revela nenhuma relação com o tipo de estrutura argumental mais externa: a distribuição dos prefixos não está correlacionada ao tipo de evento, pois os três prefixos $(a-, e N-, e S$-) ocorrem com os dois tipos de verbalizadores e com Voice [ $\pm \mathrm{ag}]$ quando licenciados em $v_{[+ \text {voice] }}$ ( $(\mathrm{cf}$.: tabela 5).

Partimos da hipótese de que o sufixo - ec- fosse a realização de um $v$ BECOME (incoativo) e que -iz- fosse a realização de um $v$ CAUS (causativo). No entanto, se tanto verbos com -ec- como verbos com -iz- veiculam tanto mudança de estado quanto uma relação de causa não faz sentido propor tal distribuição. Contudo, é fato que na superfície há uma distribuição complementar: não há verbo que contenha -ec-e - $i z$ - ao mesmo tempo: eles ocupam a mesma posição estrutural - são expoentes de $v$. Deste modo, a morfologia sufixal do PB aponta certas tendências em termos de inclusão na classe de VMEs internamente ou externamente causados, mas sua ocorrência não é consistente.

Em termos analíticos, propusemos dois tipos de verbalizadores: a) $v_{[+ \text {voice }]}$ que licencia Voice [ $\pm \mathrm{ag}]$ e que é realizado fonologicamente -iz- ou -ec- (e Ø) $\mathrm{e}$; b) $v_{\text {[-voice }]}$ que nunca licencia Voice, mas pode licenciar opcionalmente uma posição de especificador marcada como [-ag], e também pode ser realizado fonologicamente por -ec-, -iz- (e Ø). Poderíamos chamar, ao dialogar com a literatura, o primeiro $v$ de causativo e o segundo de incoativo. No entanto, lembramos que uma relação de causa e mudança (incoatividade) se estabelece na presença de ambos. Por isso, rotulamos os categorizadores de $v_{[+ \text {voice }]} \mathrm{e} v_{[- \text {voice }]}$. 
Ainda na tabela 5, se atentarmos para o fato de que os tipos 1 e 2 possuem verbalizador tipo $v_{\text {[-voice] }}$ e os demais tipos ( 3 a 6 ) possuem verbalizador de tipo $v_{[+v o i c e]}$, podemos observar as possíveis realizações sufixais desses dois verbalizadores na segunda parte da tabela (sufixos). Outras realizações para esses núcleos são possíveis, mas não estão sob o escopo deste estudo no momento ${ }^{16}$.

Se a morfologia sufixal verbal do PB fosse ativa e consistente deveríamos esperar a existência de pares alternantes em que a apresença de -ec- marcasse a versão incoativa ao passo que $\varnothing$ ou -iz- marcassem a versão causativa $\left(\right.$ amolecer $_{\text {incoativo }}$ vs. *amolar/*amolizar causativo ). Somente nesse contexto poderíamos assumir que a morfologia evidencia a presença de verbalizadores de sabores distintos. No entanto, a alternância é labile, e assumimos que a presença de -ec-apenas pode ser a indicação de uma tendência ou um resquício de uma época em que esse sufixo foi de fato produtivo como marca de incoatividade.

Tabela 5 - VMEs: tipo de evento vs. afixos.

\begin{tabular}{|c|c|c|c|c|c|c|c|c|c|c|c|c|c|c|c|c|}
\hline \multirow{3}{*}{$\begin{array}{c}\text { Evento } \\
1 .\end{array}$} & \multicolumn{6}{|c|}{ Prefixo } & \multicolumn{8}{|c|}{ Sufixo } & \multirow{2}{*}{\multicolumn{2}{|c|}{ Total }} \\
\hline & & 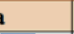 & & v & & $\mathbf{s}$ & & e & & c & & $\mathrm{iz}$ & & $x$ & & \\
\hline & 9 & $12 \%$ & 10 & $19 \%$ & 1 & $13 \%$ & 1 & $50 \%$ & 11 & $28 \%$ & 0 & $\mathbf{0 \%}$ & 8 & $9 \%$ & 20 & $15 \%$ \\
\hline 2. & 6 & $8 \%$ & 12 & $23 \%$ & 1 & $13 \%$ & 0 & $0 \%$ & 9 & $23 \%$ & 1 & $50 \%$ & 9 & $10 \%$ & 19 & $14 \%$ \\
\hline 3. & 18 & $24 \%$ & 5 & $9 \%$ & 0 & $0 \%$ & 0 & $0 \%$ & 2 & $5 \%$ & 1 & $\mathbf{5 0 \%}$ & 20 & $22 \%$ & 23 & $17 \%$ \\
\hline 4. & 16 & $21 \%$ & 5 & $9 \%$ & 1 & $13 \%$ & 0 & $0 \%$ & 2 & $5 \%$ & 0 & $0 \%$ & 20 & $22 \%$ & 22 & $16 \%$ \\
\hline 5. & 15 & $20 \%$ & 2 & $4 \%$ & 2 & $25 \%$ & 0 & $0 \%$ & 2 & $5 \%$ & 0 & $0 \%$ & 17 & $18 \%$ & 19 & $14 \%$ \\
\hline 6. & 11 & $15 \%$ & 19 & $36 \%$ & 3 & $38 \%$ & 1 & $50 \%$ & 13 & $33 \%$ & 0 & $0 \%$ & 19 & $20 \%$ & 33 & $24 \%$ \\
\hline Total & 75 & $100 \%$ & 53 & $100 \%$ & 8 & $100 \%$ & 2 & $100 \%$ & 39 & $100 \%$ & 2 & $100 \%$ & 93 & $100 \%$ & 136 & $100 \%$ \\
\hline
\end{tabular}

Recebido em: 07/12/2016

Aprovado em: 07/07/2017

Email:

Indaiá Bassani indaia.bassani@unifesp.br

\section{Referências}

ACEDO-MATELLÁN, Victor. 2006. Una aproximació sintàctica als verbs prefixats en català. Estudios Catalanes, 4:41-78.

ALEXIADOU, Artemis. 2014. The problem with internally caused change of state verbs. Linguistics, 52/4: 879-909.

ALEXIADOU, Artemis; ANAGNOSTOPOULOU, Elena; SCHÄFER, Florian. 2006. The properties of anticausatives crosslinguistically. In: FRASCARELLI, M. (Ed.) Phases of Interpretation. Berlin: Mouton.

16. Apesar de identificadas na tabela abaixo, as realizações com sufixos -e- (esverdear e assenhorear) não foram consideradas porque o foco da literatura na discussão de causa se dá na oposição entre os afixos -ec- e -iz-. 
BASSANI, Indaiá de Santana. 2011. A estrutura de eventos dos verbos morfologicamente complexos com sufixo -ec-. In: 59. SEMINÁRIO DO GRUPO DE ESTUDOS LINGUÍSTICOS DO ESTADO DE SÃO PAULO (GEL). Handout. Bauru.

2013. Uma abordagem localista para morfologia e estrutura argumental dos verbos complexos (parassintéticos) do português brasileiro. Tese (Doutorado em Letras) - Faculdade de Filosofia, Letras e Ciências Humanas, Universidade de São Paulo. São Paulo.

BASSANI, Indaiá de Santana; MINUSSI, Rafael Dias. 2015. Contra a seleção de argumentos pelas raízes: nominalizações e verbos complexos. ReVEL, 13/24: 139-173.

BURZIO, Luigi. 1986. Italian Syntax: a Government-Binding approach. Dortrecht: Reidel.

CANÇADO, Márcia; GODOY, Luisa. 2012. Representação lexical de Classes verbais do PB. Alfa, 56/1:109-135.

HALE, Ken; KEYSER, Jay. 2002. Prolegomenon to a Theory of Argument Structure. Cambridge: MIT Press.

HALLE, Morris; MARANTZ, Alec. 1993. Distributed Morphology and the pieces of inflection. In: HALE, K.; KEYSER, J. The View from Building 20. Cambrigde: MIT Press.

HARLEY, Heidi. 2008. On the causative construction. In: MIYAGAWA, S.; SAITO, M. Handbook of Japanese Linguistics. Oxford: OUP.

2007. The bipartite structure of verbs cross-linguistically, or Why Mary can't exhibit John her paintings. Write-up of a talk given at the 2007 ABRALIN Congress in Belo Horizonte, Brazil.

NEGRÃO, Esmeralda; VIOTTI, Evani. 2010. A estrutura sintática das sentenças absolutas no português brasileiro. Revista Linguística da ALFAL, 23:37-58.

OLIVEIRA, Solange. 2009. Aspectos da derivação prefixal e sufixal no português do Brasil. 2009. 252f. Tese (Doutorado em Linguística). Universidade Federal de Santa Catarina, Florianópolis.

PARSONS, Terence. 1990. Events in the semantics of English. Cambridge: The MIT Press.

PEREIRA, Rui Abel. 2007. Formação de verbos em português: afixação heterocategorial. Muenchen: Lincom Europa.

RIO-TORTO, Graça. 2004. Morfologia, Sintaxe e Semântica dos Verbos Heterocategoriais. In: RIO-TORTO, G. Verbos e Nomes em Português. Coimbra: Almedina.

SCHÄFER, Florian. 2008. The Syntax of (Anti-)Causatives. External arguments in change-of-state contexts. Amsterdam/Philadelphia: John Benjamins.

SCHER, Ana Paula; MEDEIROS, Alessandro Boechat; MINUSSI, Rafael Dias. 2011. Estrutura Argumental em Morfologia Distribuída. In: LIMA-SALLES, H. M. M.; NAVES, R.R. Estudos formais das gramáticas das línguas naturais. Goiânia: Cânone. 


\section{Anexo. Tipos de Eventos de Mudança de Estado.}

\begin{tabular}{|c|c|c|}
\hline \multicolumn{2}{|c|}{ Evento } & VMEs $^{17}$ \\
\hline \multicolumn{2}{|c|}{$\begin{array}{l}\text { Tipo 1. Evento incoativo } \\
\text { a. *\# A Maria amadureceu a fruta. } \\
\text { b. O calor amadureceu a fruta. } \\
\text { c. A fruta (*se) amadureceu. } \\
\text { d. *A fruta foi amadurecida (pela Maria/ } \\
\text { pelo calor). }\end{array}$} & $\begin{array}{l}\text { amanhecer, emagrecer, engravidar, envelhecer, } \\
\text { endurecer engordar, anoitecer, amadurecer, } \\
\text { adormecer, adoecer, apodrecer, amortecer, } \\
\text { adensar, endoidar, empalidecer, avermelhar, } \\
\text { esverdear, empapar, empedrar, emprenhar. }\end{array}$ \\
\hline \multicolumn{2}{|c|}{$\begin{array}{l}\text { Tipo 2. Evento estritamente causativo } \\
\text { a. *\# O filho enfureceu a mãe. } \\
\text { b. A briga enfureceu a mãe. } \\
\text { c. A mãe (se) enfureceu (com o filho). } \\
\text { d. * A mãe foi enfurecida (pelo filho/pela } \\
\text { briga). }\end{array}$} & $\begin{array}{l}\text { apaixonar, enriquecer, ajuizar, estremecer, } \\
\text { assemelhar, entristecer, afamar, enamorar, } \\
\text { empobrecer, enfurecer, emudecer, encolerizar, } \\
\text { agigantar, enervar, amesquinhar, enricar, } \\
\text { enraivecer, embrutecer, embravecer. }\end{array}$ \\
\hline \multirow{2}{*}{ 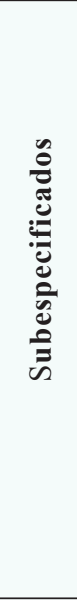 } & $\begin{array}{l}\text { Tipo 3. Evento causativo } \\
\text { subespecificado para }[ \pm \text { ag] } \\
\text { a. O professor anulou a prova. } \\
\text { b. A desonestidade dos alunos } \\
\text { anulou a prova. } \\
\text { c. A prova }\left({ }^{*} \mathrm{se}\right) \text { anulou }\left({ }^{*} \text { sozinha }{ }^{18}\right) \text {. } \\
\text { d. A prova foi anulada (pelo } \\
\text { professor). }\end{array}$ & $\begin{array}{l}\text { assegurar, aprimorar, aproximar, encobertar, } \\
\text { arriscar, associar, aquecer, anular, encurtar, } \\
\text { alongar, apressar, alargar, embelezar, atormentar, } \\
\text { abrilhantar, acobertar, endireitar, apavorar, } \\
\text { aplainarlaplanar, entorpecer, atemorizar, } \\
\text { aligeirar, avassalar. }\end{array}$ \\
\hline & $\begin{array}{l}\text { Tipo 4. Evento totalmente } \\
\text { subespecificado "Alternância total" } \\
\text { a. A esteticista amoleceu a cera. } \\
\text { b. O calor amoleceu a cera. } \\
\text { c. A cera (?se) amoleceu (sozinha). } \\
\text { d. A cera foi amolecida (pela } \\
\text { esteticista/pelo calor). }\end{array}$ & $\begin{array}{l}\text { encher, associar, acalmar, abaixar, acostumar, } \\
\text { esvaziar, alisar, afinar, amolecer, amansar, } \\
\text { afrouxar, ajuntar, abrasar, arredondar, alumiar, } \\
\text { acalentar, entortar, avivar, incandescer, } \\
\text { acovardar, encurvar, encrespar, afofar. }\end{array}$ \\
\hline \multicolumn{2}{|c|}{$\begin{array}{l}\text { Evento causativo agentivo } \\
\text { a. O frentista abasteceu o carro. } \\
\text { b. * A bomba de gasolina abasteceu o carro. } \\
\text { c. * O carro abasteceu (sozinho/ com a } \\
\text { bomba de gasolina). } \\
\text { d. O carro foi abastecido (pelo frentista/ } \\
\text { *pela bomba de gasolina). }\end{array}$} & $\begin{array}{l}\text { Esclarecer, acertar, alinhar, ajustar, aperfeiçoar, } \\
\text { acomodar, abastecer, aprontar, apropriar, } \\
\text { ajeitar, afixar, adoçar, abreviar, expropriar, } \\
\text { embebedar, amornar, apadrinhar, endeusar, } \\
\text { acolchoar. }\end{array}$ \\
\hline \multicolumn{2}{|c|}{$\begin{array}{l}\quad \text { Evento estritamente causativo com } \\
\text { Voice } \\
\text { a. *\# O chefe enobreceu o rapaz. } \\
\text { b. O trabalho enobreceu o rapaz. } \\
\text { c. O rapaz (se) enobreceu. } \\
\text { d. O rapaz foi enobrecido (pelo trabalho). }\end{array}$} & $\begin{array}{l}\text { Apurar, esquentar, enlouquecer, esfriar, agravar, } \\
\text { engrossar, atenuar, enfraquecer, envergonhar, } \\
\text { alagar, engrandecer, amaciar, abrandar, } \\
\text { evaporar, encarecer, aquietar, enrijecer, } \\
\text { enferrujar, endoidecer, enegrecer, enobrecer, } \\
\text { avolumar, emburrecer, enternecer, assenhorear, } \\
\text { enrubescer, embranquecer, ensurdecer, } \\
\text { aferventar, enlutar, extenuar, emborrachar, } \\
\text { afervorar. }\end{array}$ \\
\hline
\end{tabular}

17. Organizados por frequência.

18. Por vezes, utilizamos o advérbio sozinho na versão intransitiva para garantir que estamos testando de fato uma interpretação incoativa e para descartar a interpretação de uma sentença absoluta (Negrão e Vioti 2010). Por exemplo, a sentença “A prova anulou” é aceitável (como sentença absoluta), mas esse verbo não aceita a modificação por sozinho(a) e nem o uso de se: A prova (*se) anulou (*sozinha). 